J. Northw. Atl. Fish. Sci., Vol. 33: 161-190

\title{
Developing Alternative Indices of Reproductive Potential for Use in Fisheries Management: Case Studies for Stocks Spanning an Information Gradient
}

\author{
C. Tara Marshall ${ }^{1}$ \\ Institute of Marine Research, P.O. Box 1870 Nordnes, N-5817 Bergen, Norway
}

Loretta O'Brien

National Marine Fisheries Service, Northeast Fisheries Science Center, Woods Hole Laboratory

166 Water Street, Woods Hole, Massachusetts, 02543 USA

Jonna Tomkiewicz ${ }^{2}$, Friedrich W. Köster ${ }^{2}$ and Gerd Kraus

Institute for Marine Sciences, Düsternbrooker Weg 20, D-24105, Kiel, Germany

Gudrun Marteinsdottir

University of Iceland, Dept. of Biology, Grensasvegur 12, 108 Reykjavik, Iceland

M. Joanne Morgan

Science Branch, Dept. of Fisheries and Oceans, P. O. Box 5667, St. John's, NL A1C 5X1, Canada

Francisco Saborido-Rey

Institute of Marine Research, Eduardo Cabello 6, 36208 Vigo, Spain

Julia L. Blanchard

Center for Environment, Fisheries and Aquaculture Science, Pakefield Rd., NR33 0HT Lowestoft, Suffolk, UK

\author{
David H. Secor \\ Chesapeake Biological Laboratory, University of Maryland Center for Environmental Science \\ P. O. Box 38, Solomon, MD 20688, USA \\ Peter J. Wright \\ Marine Laboratory, P.O. Box 101, Victoria Rd., Aberdeen, Scotland, UK \\ Nina V. Mukhina \\ Polar Research Institute of Marine Fisheries and Oceanography \\ 6 Knipovich St., Murmansk, 183763, Russia \\ and \\ Höskuldur Björnsson \\ Marine Research Institute, P. O. Box 1390, Skulagata 4, 121 Reykjavik, Iceland
}

\begin{abstract}
There is accumulating evidence to suggest that spawning stock biomass (SSB) may not be directly proportional to reproductive potential. The wide-ranging implications of this conclusion necessitate that it be tested for as many stocks as possible. Undertaking such tests is complicated by the fact that fish stocks vary in the amount and type of information that is available to estimate reproductive potential. In this review, nine stocks illustrate the range of
\end{abstract}

Present address: University of Aberdeen, Zoology Dept., Tillydrone Ave., Aberdeen, AB24 2TZ, Scotland, UK.

2 Present address: Danish Institute for Fisheries Research, Charlottenlund Castle, DK-2920, Charlottenlund, Denmark 
approaches that are being taken to developing alternative indices of reproductive potential from existing data resources. Three stocks had sufficient data to reconstruct a time series of total egg production (TEP), whereas, the remaining stocks were limited to estimating proxies for stock reproductive potential. For some of the case studies the alternative indices explained a higher amount of recruitment variation than did SSB. Other case studies provided evidence that characteristics of the spawning stock, e.g. age diversity and female-only SSB, influence recruitment in ways that are not properly accounted for by using SSB as the sole index of reproductive potential. This is further evidence that the assumption of proportionality between SSB and TEP is invalid. The data-rich stocks showed the relationship between SSB and TEP to be variable and characterized by distinct time trends. This variability will impact the ability of biomass-based reference points to conserve reproductive potential. Consequently, management protocols should be adapted to incorporate the detailed information on reproductive potential that is increasingly becoming available rather than being restricted to approaches that have been designed for data-poor situations.

Key words: age diversity index, cod, egg production, fecundity, fisheries management, recruitment, reference points, reproductive potential

\section{Introduction}

One of the basic goals of fisheries management is to conserve sufficient reproductive potential of a stock to allow for sustainable exploitation. In the precautionary approach to fisheries management harvest control rules are developed and implemented to achieve this goal (Caddy, MS 1999). For many marine fish stocks harvest control rules are defined using reference points for both spawning stock biomass (SSB) and fishing mortality (NAFO, MS 1998; ICES ACFM, MS 1998a). In simple terms, a limit reference point indicates a level that should be avoided because the probability of negative consequences (such as impaired recruitment) is unacceptably high when that level is violated. Threshold reference points indicate a value beyond which the stock is considered to be in an acceptable area and wherein management targets may be set. Reference points are frequently established from the stock-recruit relationship (Table 1). Although there appears to be a central tendency for recruitment to be related to SSB (Myers and Barrowman, 1996; Brodziak et al., 2001), in practice the high degree of variability that is typical of many stock-recruit relationships impedes identifying either an underlying functional form or a specific level of SSB at which recruitment is impaired. If SSB over-estimates the reproductive potential of the stock, then the reference points derived using SSB will over-estimate the resiliency of the stock to fishing (Murawski et al., 2001).

One source of uncertainty in the stock-recruit relationship is the assumption that SSB is proportional to the reproductive potential of the stock (Rothschild and Fogarty, 1989; Trippel, 1999). It is equivalent to assuming that the relative fecundity (number of eggs produced per unit weight) of the stock is constant both temporally and spatially and that all eggs have the same probability of survival. The former assumption has long been recognized as invalid at the individual-level (Oosthuizen and Daan, 1974; Ware, 1980). Several recent studies have documented a high degree of variability in the relative fecundity of individual Atlantic cod (Gadus morhua) (Kjesbu et al., 1998, Kraus et al., 2000, Marteinsdottir and Begg, 2002). At the stocklevel, skipped spawning and atresia have been observed (Kjesbu et al., 1991; Witthames and Greer Walker 1995; Ma et al., 1998; Marshall et al., 1998; Bromley et al., 2000; Rideout et al., 2000). As both are observed in fish of poor condition, a high degree of interannual variability in per capita food abundance is likely to increase the divergence between SSB and total egg production (TEP). Reproductive potential is also affected by shifts in size composition because large/old spawners have higher relative fecundities, higher egg quality, and/or specific spawning behaviours that can make a disproportionately high contribution to recruitment (Zastrow et al., 1989; Lambert, 1990; Secor, 2000a, b; Marteinsdottir and Begg, 2002). Likewise, shifts in the size composition of the spawning stock towards smaller size classes can result in the sex ratios becoming progressively skewed towards males because of their earlier maturation (Ajiad et al., 1999; Jakobsen and Ajiad, 1999). Thus, maturity ogives that do not account for gender could cause SSB to be disproportionately influenced by males. Furthermore, spatial and/or temporal segregation of spawners of differing sizes or condition can interact with the physical environment such that the surviving eggs have a higher probability of originating from sub-units of the stock (Vallin and Nissling, 2000; Begg and Marteinsdottir, 2003). 
TABLE 1. Commonly used reference points for the management of marine fisheries (adapted from ICES, MS 1997 and NAFO, MS 1997).

\begin{tabular}{|c|c|}
\hline $\begin{array}{c}\text { Referenc } \\
\text { Point }\end{array}$ & Definition \\
\hline & $F$ at which the slope of the $\mathrm{Y} / \mathrm{R}$ curve is $10 \%$ of its value near the origin \\
\hline & $F$ giving the maximum yield on a $\mathrm{Y} / \mathrm{R}$ curve \\
\hline$F_{\text {low }}$ & $F$ corresponding to a SSB/R equal to the inverse of the $10 \%$ percentile of the observed $\mathrm{R} / \mathrm{SSB}$ \\
\hline$F_{\text {med }}$ & $F$ corresponding to a SSB $/ \mathrm{R}$ equal to the inverse of the $50 \%$ percentile of the observed R/SSB \\
\hline igh & $F$ corresponding to a SSB/R equal to the inverse of the $90 \%$ percentile of the observed $\mathrm{R} / \mathrm{SSB}$ \\
\hline MSY & $\begin{array}{l}F \text { corresponding to a Maximum Sustainable Yield from a production model or from an age-based analysis } \\
\text { using a stock-recruitment model }\end{array}$ \\
\hline$F_{40 \% S P R}$ & $F$ corresponding to a level of $\mathrm{SSB} / \mathrm{R}$ which is $40 \%$ of the $\mathrm{SSB} / \mathrm{R}$ obtained when $F=0$ \\
\hline$F_{\text {crash }}^{40 \text { \% }}$ & $\begin{array}{l}F \text { corresponding to the higher intersection of the equilibrium yield with the } F \text { axis as estimated by a production } \\
\text { model; could also be expressed as the tangent through the origin of a stock-recruit relationship }\end{array}$ \\
\hline & $F$ corresponding to a $\mathrm{SSB} / \mathrm{R}$ equal to the inverse of $\mathrm{R} / \mathrm{SSB}$ at the lowest observed $\mathrm{SSB}\left(B_{\text {loss }}\right)$ \\
\hline$F_{\text {lim }}$ & $F$ determined either objectively (e.g. lowest observed $F$ ) or subjectively based on stock history \\
\hline & $F$ determined either objectively (e.g. with reference to $F_{l i m}$ value) or subjectively based on stock history \\
\hline & $\begin{array}{l}F \text { that acts as a buffer to ensure that there is a high probability that } F_{\text {lim }} \text { is not reached } \\
\text { target } F \text { which depends on management objectives: corresponds to a level below or equal to } F_{\text {b }}\end{array}$ \\
\hline$B$ target & $\begin{array}{l}\text { omass corresponding to Maximum Sustainable Yield from a production model or from an age-based analysis } \\
\text { ing a stock-recruitment model }\end{array}$ \\
\hline ABA & alue of SSB below which the probability of reduced recruitment increases \\
\hline$B_{50 \% R}$ & $\begin{array}{l}\text { the level of SSB at which average recruitment is one half of the maximum of the underlying stock-recruit } \\
\text { relationship }\end{array}$ \\
\hline lo & lowest observed spawning stock size \\
\hline$B_{\text {lim }}$ & $\begin{array}{l}\text { in general, the SSB level that the stock should not be allowed to fall below; in some cases the level of SSB } \\
\text { below which recruitment is impaired }\end{array}$ \\
\hline$B_{p a}$ & the level of SSB associated with a very low risk of falling below $B_{\text {lim }}$ value \\
\hline$B_{\text {buf }}$ & $\mathrm{SB}$ that acts as a buffer to ensure that there is a high probability that $B_{\text {lim }}$ is not reac \\
\hline$B_{\text {target }}$ & $\begin{array}{l}\text { the target recovery level. In accord with Annex II of the UN Agreement of the Conservation and Management } \\
\text { of Straddling Fish Stocks and Highly Migratory Fish stocks, for overfished stocks this is the SSB which } \\
\text { would produce maximum sustainable yield }\end{array}$ \\
\hline
\end{tabular}

As a result of increased knowledge about the sources and magnitude of variability in TEP, the stockrecruit relationships for several stocks are currently being re-evaluated using alternative indices of reproductive potential (Marteinsdottir and Thorarinsson, 1998; Marshall et al., 1998, 2000; Köster et al., 2003). Two general categories of indices are possible: i) stockbased indices estimated from attributes of the spawners which approximate potential TEP; and ii) survey-based indices estimated from egg abundances measured during ichthyoplankton surveys which approximate realized TEP. Both categories of indices can be estimated either on an absolute scale (e.g. estimates of SSB or TEP) or on a relative scale (e.g. proxies such as age diversity or relative egg abundance). Examples of stock-based indices include: i) fecundity-based estimates of potential TEP by the stock (Köster et al., 2001a); ii) bioenergetic indices (Painting et al., 1998; Henderson et al., 2000; Marshall et al., 2000); iii) refinements to SSB through the incorporation of year-, area- and/or gender-specific information on maturityand weight-at-age (Tomkiewicz et al., MS 1997); iv) proxies derived from long time series describing the condition_of individual spawners (Marshall and Frank, 1999; Blanchard, MS 2000); and v) proxies, such as age diversity indices, derived from basic demographic data provided by stock assessments (Lambert, 1990; Marteinsdottir and Thorarinsson, 1998; Secor, 2000a; O'Brien et al., 2003). Examples of survey-based indices include: i) estimates of egg production (Brodeur et al., 1996; Köster et al., 2001a); ii) relative egg abundance (Morse, MS 1994; Mukhina et al., 2003); and iii) proportions of tows containing eggs (Uphoff, 1997). For some stocks a combination of stock- and survey-based indices is proving useful for evaluating the relationship between potential and realized TEP (Köster et al., 2003; Mukhina et al., 2003).

This review illustrates several of the approaches being used to quantify reproductive potential by 
presenting separate case studies for nine stocks distributed throughout the Atlantic Ocean and in the Baltic Sea. The majority of these stocks are currently outside safe biological limits or under moratoria (Table 2 ) although one has recovered from an earlier collapse. The stocks span an information gradient in the sense of having variable amounts of relevant data. Data-rich stocks could be considered to be those having sufficient fecundity data to permit estimating TEP on time scales that are comparable to those represented in the traditional stock-recruit relationship. Data-poor stocks could be considered as those that are restricted to proxies that can be derived directly from the analytical assessment (e.g. age diversity indices, female-only SSB) (Lambert et al., 2003). The case studies presented here were not categorized specifically according to richness because in several cases the alternative indices presented herein under-represent the databases that are available. However, the case studies are presented approximately in descending order of the number and complexity of the indices that are described for the case study in this review. A more objective approach to ranking data availability for stocks in the Northwest Atlantic can be found in Tomkiewicz et al. (2003).

Each case study follows a similar format: the current management protocol is summarized with specific reference to the harvest control rules used, the alternative index of reproductive potential is described, and possible approaches for incorporating this information into stock management are indicated. There are three general approaches to evaluating the alternative indices: i) the index can be compared to a survey-based estimate of egg production; ii) the index can replace SSB in the bivariate stock-recruit model; or iii) the index can be used as an additional independent variable in a multivariate stock-recruit model. Each case study used at least one of these approaches to evaluating the indices. The case studies were not pre-selected to include only cases where improvements to the stockrecruit relationship were found. Rather, both positive and negative results are presented because all results were felt to be informative at this early, exploratory stage of inquiry. The general discussion identifies several key issues that must be addressed before the alternative indices can be fully integrated with existing management protocols.

\section{Case Studies}

\section{Baltic cod}

Current management protocol. The management of cod in the central Baltic (ICES Sub-divisions 25-32) has established $B_{p a}$ and $B_{l i m}$ values equal to 240000 tons and 160000 tons, respectively (ICES ACFM, MS 1998b). The $B_{p a}$ equals the former MBAL value (ICES, MS 1996) that was calculated using a constant maturity ogive and values of weight-at-age in the stock that were constant over the whole (ages 1-3) or part of the time series (ages 4-8). The $B_{\text {lim }}$ was estimated as follows:

$$
B_{l i m}=B_{p a} e^{(-1.645 \sigma)}
$$

where $\sigma$ is the standard error of a cod biomass index derived from the Baltic International Trawl Survey (BITS). In 1998, the ICES Baltic Fisheries Assessment Working Group replaced the constant maturity ogive with a time series of area- and period- or year-specific ogives resulting in a substantial downward revision of the SSB values (ICES ACFM, MS 1998b), however, the biomass reference points were not revised.

Since 1998 the stock-recruit relationship for Baltic cod (Fig. 1) has been divided into a period where oxygen conditions were favourable for egg and larval survival (1966-80) and a period of unfavorable oxygen conditions (1981 to present). The $F_{p a}$ of 0.6 was derived from medium-term simulations applying a stockrecruit relationship fitted only to data covering the latter time period (ICES ACFM, MS 1998b). These simulations used average (1995-97) values of stock weight- and maturity-at-age and, thus, the $F_{p a}$ value does not account for the true magnitude of interannual variability in growth and maturation. The $F_{\text {lim }}$ corresponds to the $F_{\text {med }}$ value of 0.96 that was derived from a stochastic stock-recruit relationship that included the 1966-95 year-classes (ICES ACFM, MS 1998b).

Estimating stock reproductive potential. Areaspecific estimates of weight-at-age are available by quarter as input to a Multispecies Virtual Population Analysis (MSVPA) that discriminates between the main spawning areas (Sub-divisions 25, 26 and 28) that account for $90-98 \%$ of the annual catch (Köster et al., 2001a). To correct for the shift towards later spawning time that occurred during the late-1980s and early-1990s (Wieland et al., 2000), the MSVPA abundance- and weight-at-age values were adjusted so that they correspond to peak spawning times. Historical and recent data on sex ratios and gender-specific maturity have also been compiled (Tomkiewicz et al., MS 1997) and show that: i) males generally mature earlier; ii) maturity at age varies spatially and temporally; and iii) the proportion of males decreases with increasing age. These data have been used to re-calculate SSB and female-only SSB for each sub-division (Köster et $a l ., 2001 \mathrm{~b}$ ). The SSB values for the aggregated stock can therefore be obtained by integrating across subdivisions. 
Marshall et al.: Developing Alternative Indices

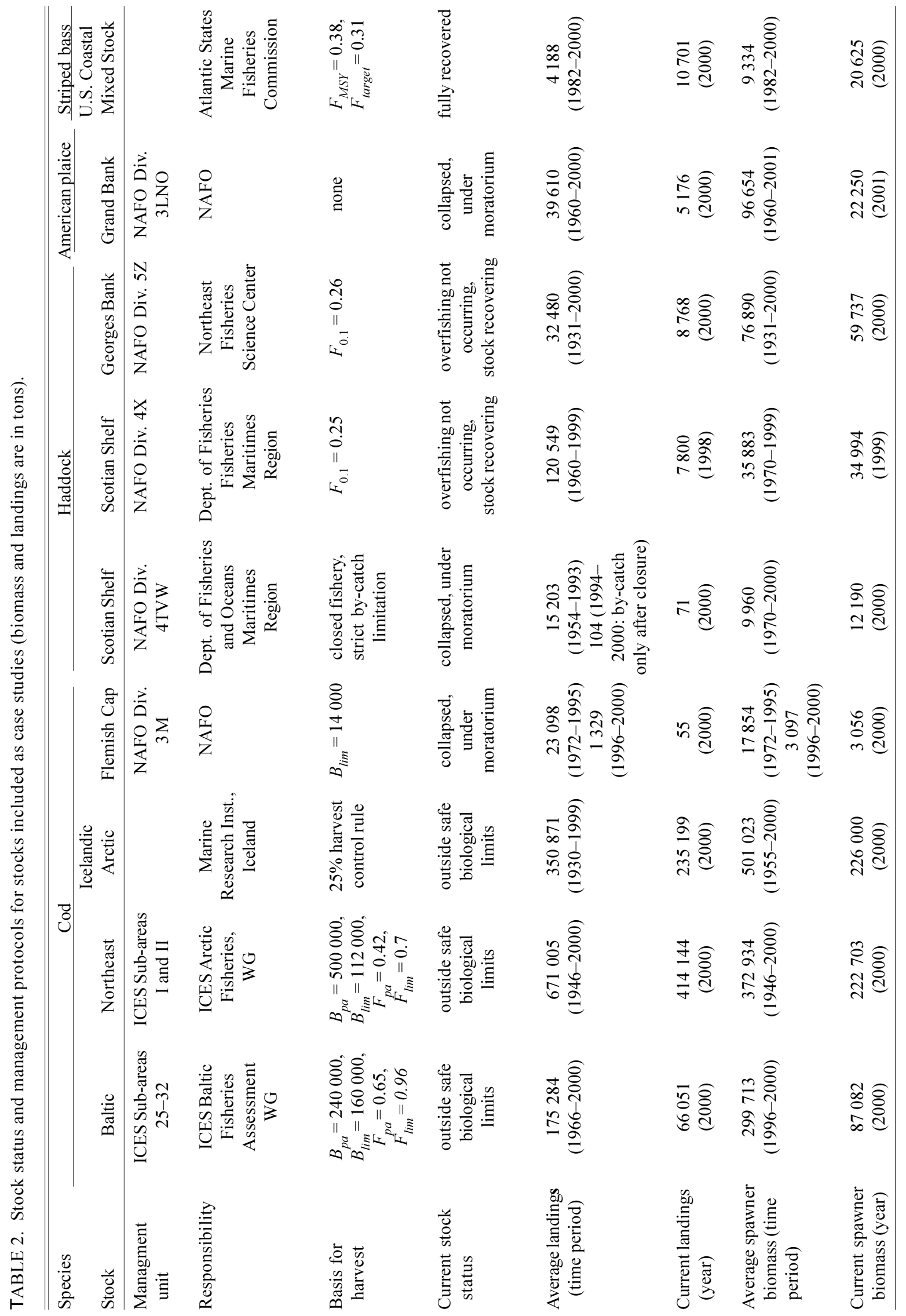


Fecundity data are available from several sources and time periods (e.g. Shapiro, 1988; Bleil and Oeberst, MS 1996; Kraus et al., 2000; 2002). Intraannually, relative fecundity is independent of size and age and does not vary between spawning areas or between earlyand late-spawners within spawning seasons (Kraus et al., 2000). However, relative fecundity varies significantly among years with the interannual variation being significantly related $\left(r^{2}=0.72, P=0.01, n=11\right)$ to clupeid prey availability expressed relative to adult cod biomass (Fig. 2). Potential TEP by the stock was therefore estimated by applying modeled values of relative fecundity (Kraus et al., 2000) to the female-only SSB.

Ichthyoplankton surveys have been conducted at regular intervals throughout the spawning season (Wieland, 1995). Egg abundances were high during the 1970s then declined to low levels in the 1980s and 1990s with an intervening peak in 1994-95 (Fig. 3). Abundance has always been highest in Sub-division 25. Low abundances have been observed in Sub-divisions 26 and 28 since the mid-1980s. It is unclear whether this is due to the loss of cod eggs from the water column because the low ambient salinity prevents them from reaching neutral buoyancy. Consequently, only the egg abundance data from Sub-division 25 were used to estimate egg production rates. Two different time series of the daily realized egg production during the main spawning time (RDEP) exist: i) RDEP of the earliest egg stage (IA) based on years with four to six surveys (Köster et al., 2001a); and ii) RDEP of early egg stage I based on years having a minimum of three surveys (Köster $e t$ al., 2003).

Because of the relative richness of the databases for Baltic cod, the analytical approach that has been taken to identifying sources of recruitment variability is to compare abundances at adjacent early life history stages in a manner similar to a Paulik diagram (Köster et al., 2003). Accordingly, different stock-based indices of reproductive potential were evaluated by comparing them to RDEP estimated for Sub-division 25 (Köster et al., 2003). The stock-based indices included: i) SSB based on a constant maturity ogive (ICES, MS 1996); ii) SSB based on year- (or period-) and area-specific maturity ogives (Tomkiewicz et al., MS 1997; CORE, MS 1998); iii) female-only SSB (Tomkiewicz et al., MS 1997; CORE, MS 1998); and iv) potential TEP estimated from the female-only SSB as described above. There was no relationship $\left(r^{2}=0.03, P=0.488, n=16\right)$ between the SSB computed on the basis of the previously used constant maturity ogive and RDEP of egg stage I (Fig. 4a; Köster et al., 2003). However, the correlation with RDEP became significant $\left(r^{2}=0.30\right.$,

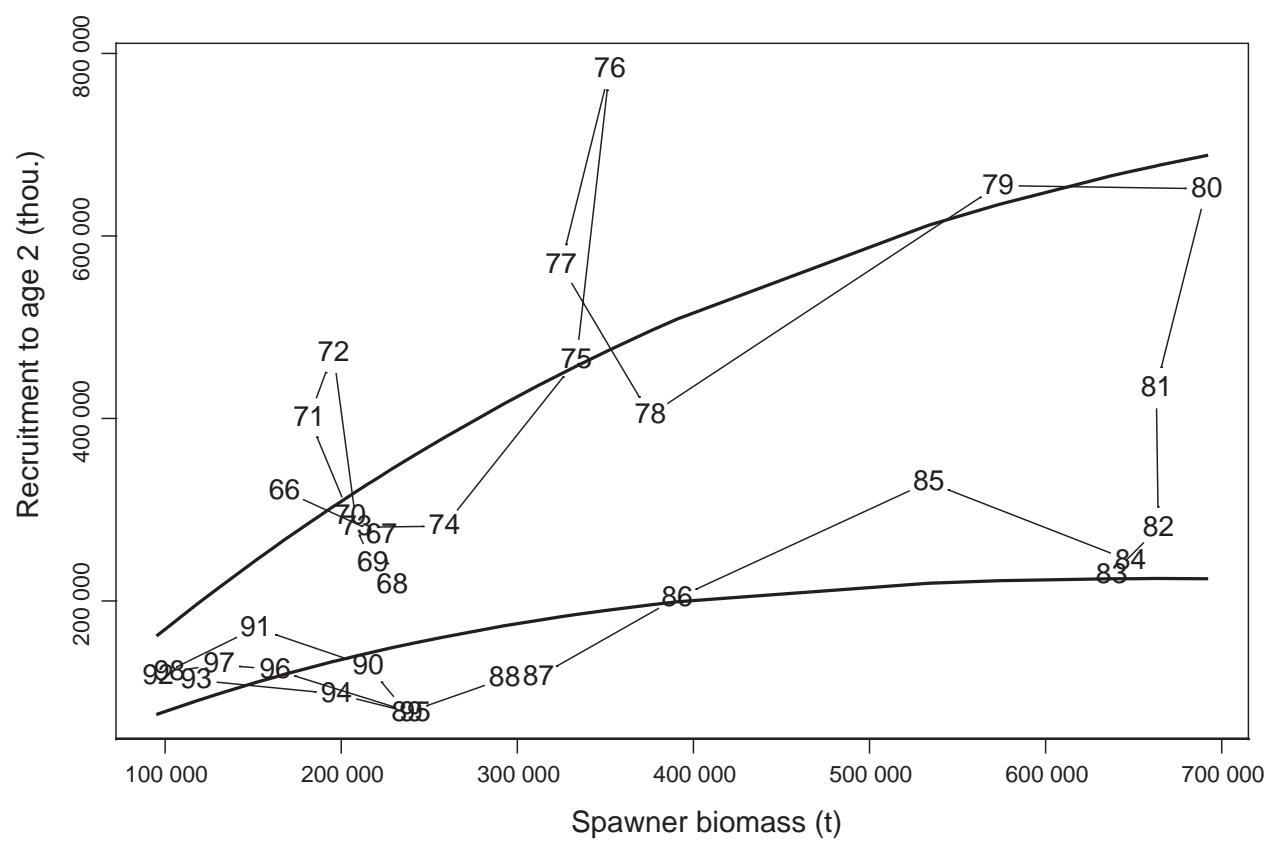

Fig. 1. Stock-recruitment relationships for the Baltic cod stock (data source: ICES ACFM, MS 2001a). The data points are labeled by year-class. The curves shown are Ricker curves fit to data from 1966-80 and 1982-2000, separately. 


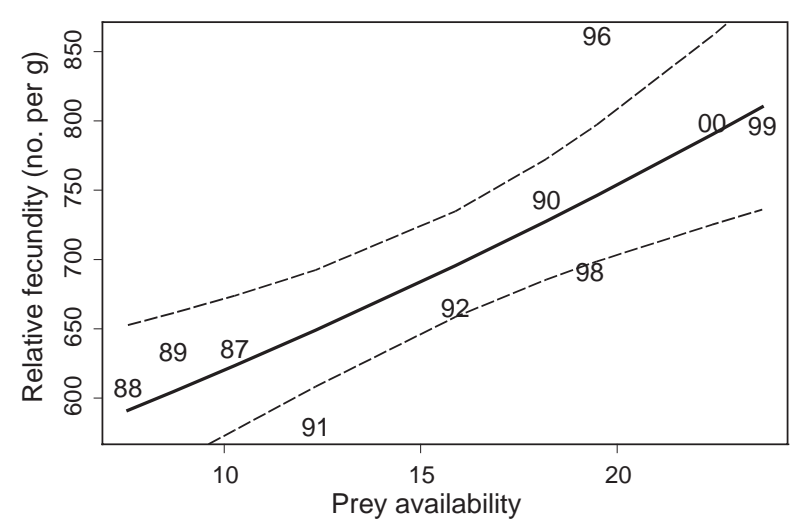

Fig. 2. The relationship between the relative fecundity of Baltic cod (number of eggs per g total body weight) and prey availability expressed as the total biomass of sprat and herring age $0-2$ divided by adult cod biomass. Observations (labeled by year), modeled relationship (solid line) and $95 \%$ confidence intervals (dashed line) are shown. Fecundity relationship is from Kraus et al. (2002).

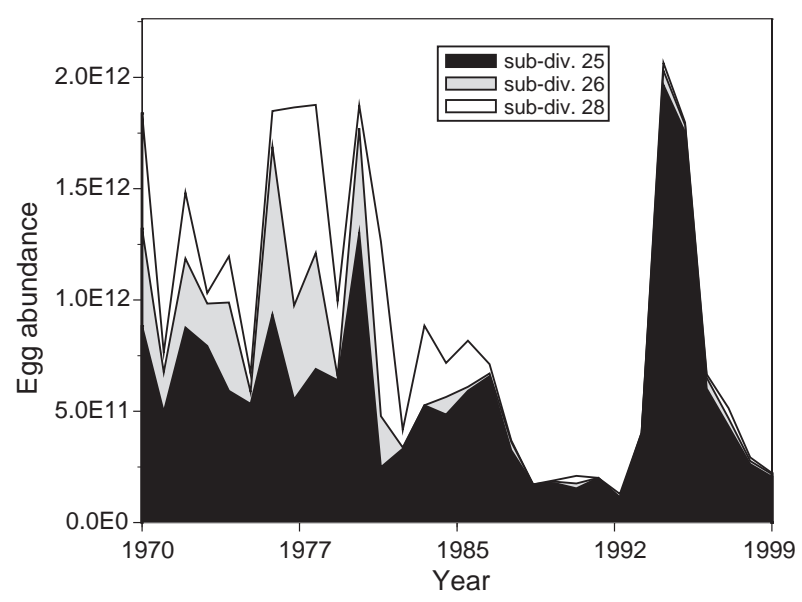

Fig. 3. Time series of the total abundance of cod eggs in ICES Sub-divisions 25, 26 and 28 of the central Baltic Sea during the main spawning period (month of peak spawning \pm one month).

$P=0.027)$ when year- (or period-) and area-specific maturity ogives were used to estimate the SSB (Fig. $4 \mathrm{~b})$ and the significance level increased substantially $\left(r^{2}=0.61, P<0.001\right)$ when female-only SSB was used (Fig. 4c; Köster et al., 2003). A small improvement to the fit ( $\left.r^{2}=0.63, P<0.001\right)$ was obtained using the potential TEP of the stock (Fig. 4d). These results suggest that part of the variability in the stock-recruit relationship currently used by management (Fig. 4b) results from using an index of reproductive potential that does not properly account for the magnitude of variability in growth, maturity, sex structure and fecundity on TEP.

Incorporating this information into stock management. Most of the current biological reference points were calculated using values of SSB estimated with constant maturity ogives estimated for females and males combined. Consequently, a review of the biological reference points for this stock should be undertaken using the revised SSB time series. Substantial improvements to explaining variability in RDEP were achieved using female-only SSB or the potential TEP. These alternative indices could therefore be used to evaluate new values proposed for biomass reference points and/or establish alternative reference points.

It should be noted that the weight-at-age term is critical to estimating both female-only SSB and potential TEP (the latter being the product of two weightdependent terms: female-only SSB and relative fecundity). The present assessment (ICES ACFM, MS 2001a) utilizes weight-at-age in the stock obtained from the BITS conducted in first quarter. Given that spawning takes place in summer, weight data from the second or third quarters are more relevant for the estimation of reproductive potential. Female-only weight data from surveys would be required to test whether the explanatory power of female-only SSB and TEP estimates could be improved by factoring in sexually dimorphic growth.

The alternative indices of reproductive potential have been used to develop environmentally-sensitive recruitment models (Fig. 5) which are of potential utility for medium-term predictions because they explain a higher portion of the recruitment variability than the models that are currently used. These models combine stock-based estimates of the potential TEP with processes such as egg mortality in relation to oxygen conditions, predation by clupeids and transport to suitable nursery areas. Models were developed for Subdivisions 25,26 and 28 using area-disaggregated estimates of the abundance of age groups 0 and 1 from the MSVPA as the dependent variable. The recruitment at age 0 predicted by the stock-recruit relationships summed across areas agrees well with the recruitment values from the MSVPA $\left(r^{2}=0.72, P<0.001, n=20\right.$; Fig. 5 ) except for one outlying year-class (Köster et al., 2001a). The predicted 0 -group recruitment values from 1996 to 1999 were reasonably close to the observed (Fig. 5a; Köster et al., 2003). As a further test of the models, predicted recruitment at age 1 (corrected for 

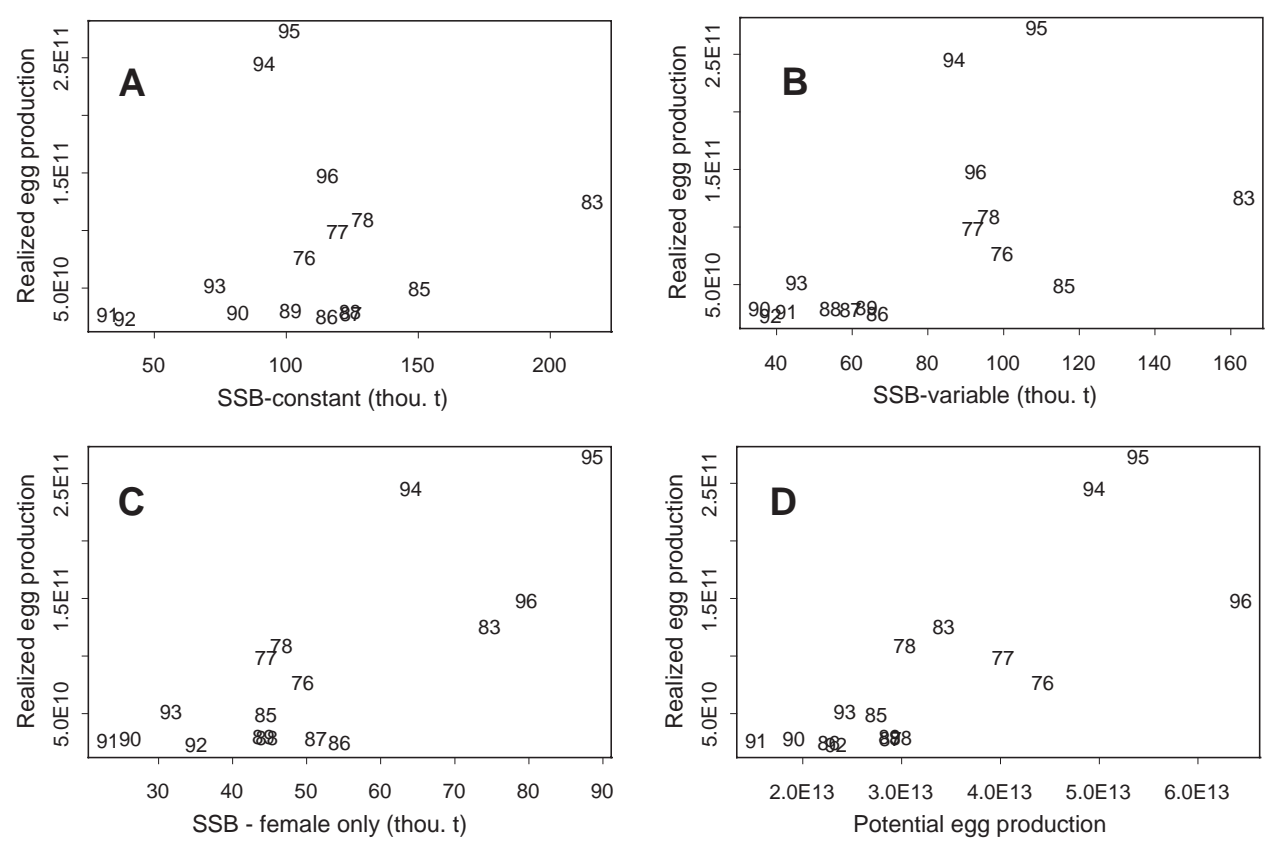

Fig. 4. The relationship between different stock-derived indices of reproductive potential and estimates of realized daily egg production of Baltic cod obtained from ichthyoplankton surveys conducted during the main spawning time (Sub-division 25 only). a) spawner biomass (SSB) estimated using constant maturity ogive, b) SSB estimated using year(period-) specific maturity ogives, c) female-only SSB, and d) and potential TEP. Observations are labeled by year-class.

cannibalism, Köster et al., 2001a, b) was compared with recruitment indices obtained from the BITS (Sparholt and Tomkiewicz, 2000). The time trends of decreasing recruitment throughout the first half of the 1980s and increasing recruitment in the 1990s are similar except for the years 1995 to 1998 (Fig. 5b). The poorer fit observed for the most recent time period may indicate that there is a problem within the recruitment index from the bottom trawl survey caused by a shift in spawning time.

\section{Northeast Arctic cod}

Current management protocol. The management for Northeast Arctic cod defines both limit and threshold reference points for both SSB and fishing mortality. The current value of $B_{l i m}$ (112 000 tons) corresponds to the lowest SSB value in the time series (i.e. $B_{\text {loss }}$ ) while the $B_{p a}$ value has been set at the former MBAL value of 500000 tons (ICES ACFM, MS 1999). The $F_{\text {lim }}$ value $(0.70)$ approximates the median value of $F_{\text {loss }}$ (ICES ACFM, MS 1999), whereas, the $F_{p a}$ value (0.42) corresponds to the 5 th percentile of $F_{\text {loss }}$. These reference points influence scientific advice and management decisions through medium-term (5-year) stock projections in which the output variable is the probability of SSB falling below the $B_{p a}$ under a variety of harvesting scenarios including $F_{p a}$. Stochasticity is incorporated through uncertainty in the stock estimates of numbers-at-age and recruitment while the growth terms (maturity- and weight-at-age) are treated as constants and set equal to the average of the three most recent years.

The indeterminate nature of the biomass-based stock-recruit relationship (Fig. 6a) makes it difficult to establish a SSB value below which recruitment is impaired. For example, four years having high recruitment $(1950,1963,1964$ and 1970) are associated with SSB values considerably less than the $B_{p a}$. Prior to 2001 , SSB values for the pre-survey time period were estimated using knife-edge maturity ogives (1946-81) and constant weight-at-age values (1946-82). Because the $B_{l i m}$ and $B_{p \mathrm{a}}$ have been derived from this SSB time series they are insensitive to the true effect that variation in growth has on stock dynamics.

In reality, the stock undergoes large and rapid fluctuations in growth. In 2001, the ICES Arctic Fisheries Working Group (AFWG) compiled historical Russian and Norwegian data to develop year-specific values for maturity- and weight-at-age for the pre-survey time period. Replacing the constant values with these year- 

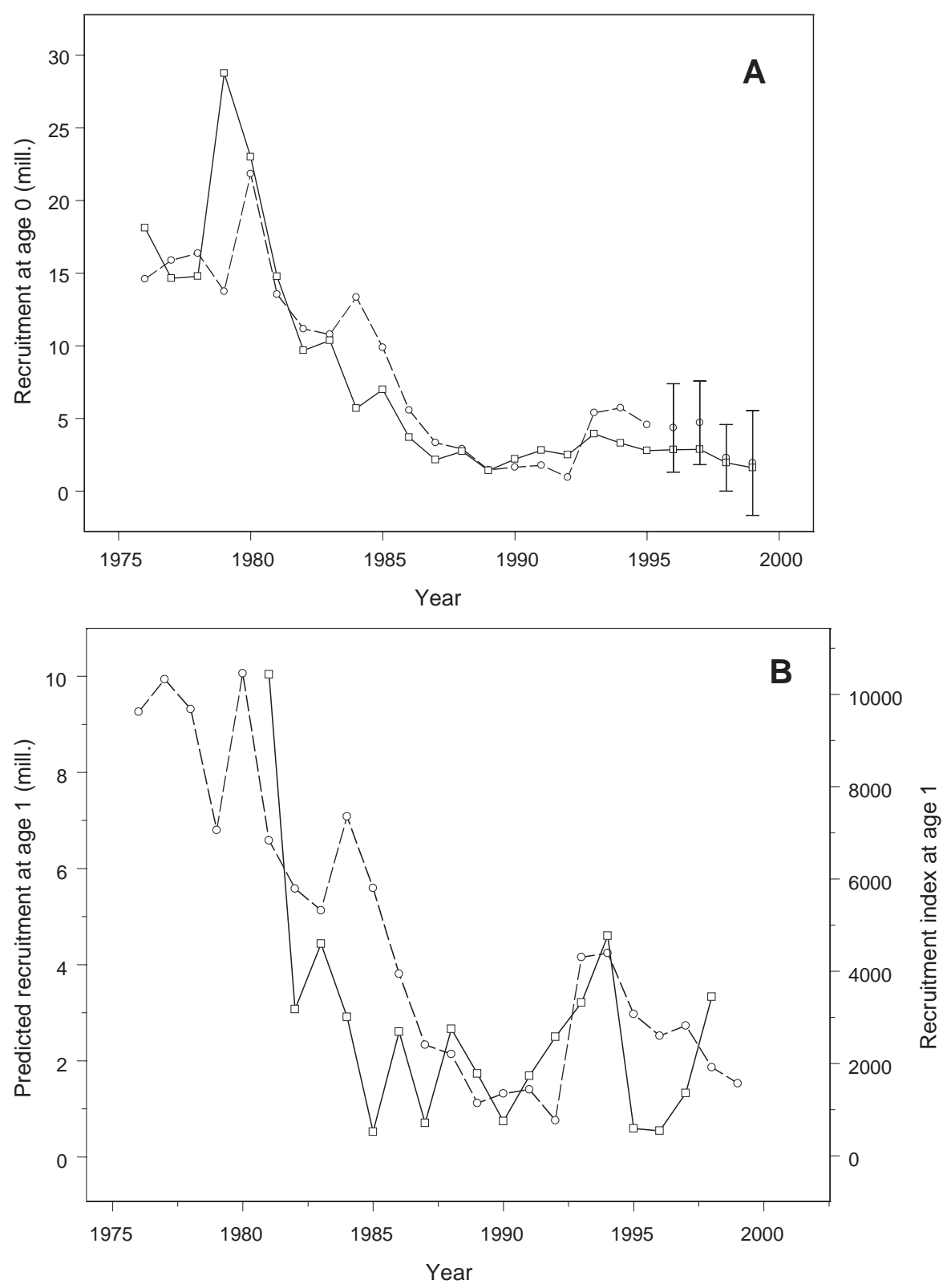

Fig. 5. Time series of recruitment of Baltic cod. a) recruitment at age 0 estimated from a Multi-species VPA (open squares, solid line) and predicted by a recruitment model which was developed for the time period 1976-95 based on estimated potential TEP (open circles, dashed line). Predictions for 1996-99 are shown with $95 \%$ confidence limits; and $\mathbf{b}$ ) recruitment index at age 1 for Sub-divisions 25,26 and 28 from the first quarter bottom trawl survey (open squares, solid line) and predicted recruitment estimated using a model similar to that used in the upper panel but which includes an additional term for cannibalism mortality of 0-group cod (open circles, dashed line).

specific values led to a substantial downward revision of SSB values such that the long-term mean decreased from 577425 tons (ICES ACFM, MS 2001b) to 372934 tons (ICES ACFM, MS 2001c).
The revision to the SSB time series as well as the high degree of variability associated with both the former and current stock-recruit relationships prompted concern about the appropriateness of the current 

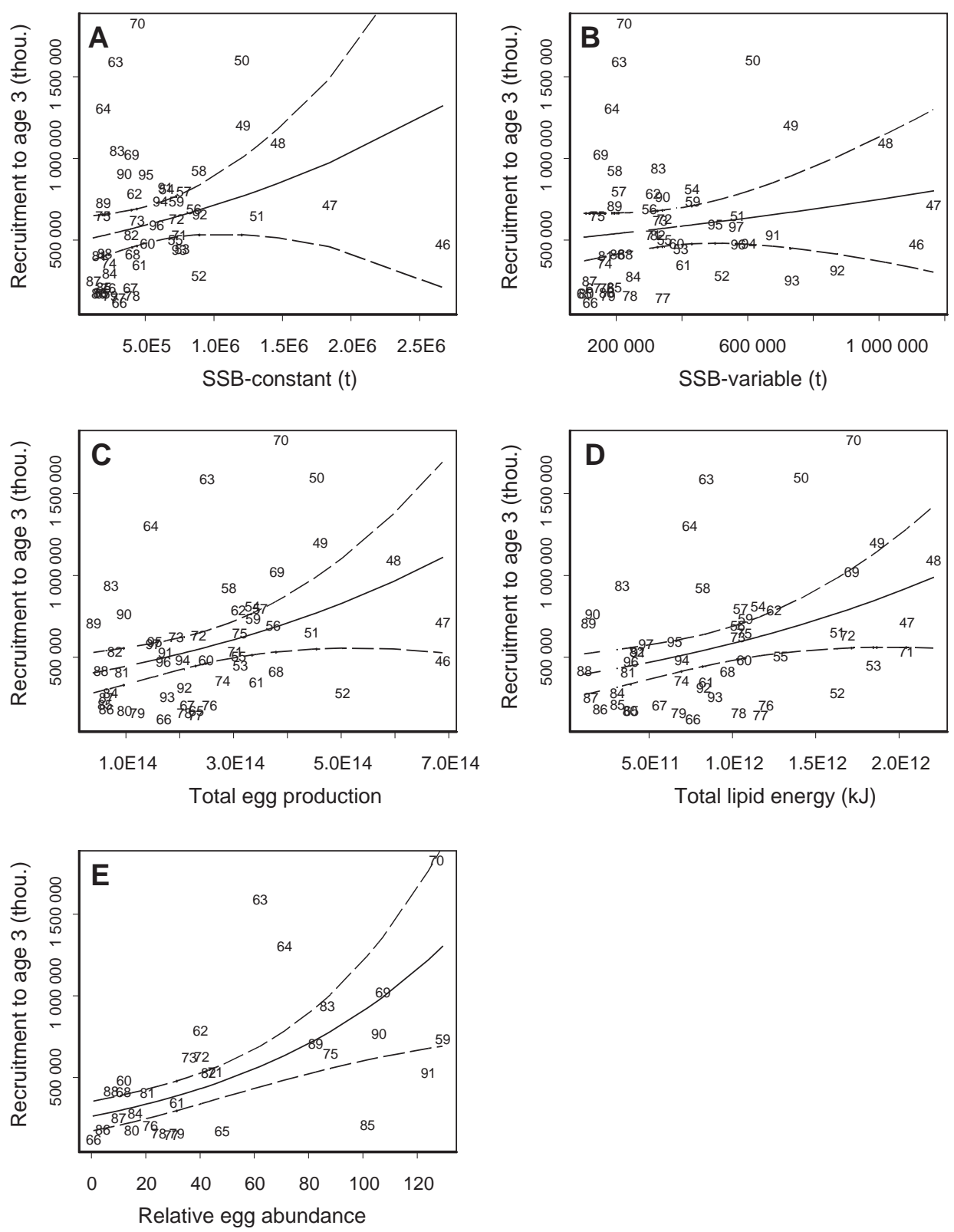

Fig. 6. The stock/recruit relationship for Northeast Arctic cod using different indices for reproductive potential. a) SSB calculated with constant values of proportion mature and weight-at-age for pre-survey time period (ICES ACFM, MS 2001b), b) SSB calculated with year-specific values of proportion mature- and weight-at-age for the full time series (ICES ACFM, MS 2001c), c) TEP (Marshall et al., unpub. data), d) total lipid energy in livers of mature females (from Marshall et al., 2000), and e) relative egg abundance (Mukhina, MS 1999). The recruitment index used is the abundance at age 3 . Observations are labeled by year-class. The generalized linear model (family $=$ gamma, link $=\log$ ) and $95 \%$ confidence intervals are shown for each.

biomass reference points (ICES ACFM, MS 2001b, c). New methodology for deriving precautionary reference points (ICES ACFM, MS 2003a) was applied to derive new values of $B_{l i m}, B_{p a}, F_{l i m}$ and $F_{p a}$ using the revised
SSB time series (ICES ACFM, MS 2003b). The proposed values were used in the most recent assessment of stock status (ICES ACFM, MS 2003c), however, they have yet to be formally adopted. 
Estimating stock reproductive potential. As noted above, historical data from Russian and Norwegian sources were used to replace the constant values of maturity- and weight-at-age with year-specific values. The pattern of variability in the revised stockrecruit relationship (Fig. 6b) is similar to the relationship obtained using the original SSB values (Fig. 6a). As before, the high recruitment values in 1963,1964 and 1970 are associated with values of SSB well below the $B_{p a}$ and nearer to the $B_{\text {lim }}$.

Because reproductive traits such as maturity and fecundity are length- rather than age-dependent, TEP was estimated by converting the VPA numbers-at-age (1946-2000) to numbers-at-length using age/length keys developed from Norwegian sources. Length-dependent values of proportion of females were used to partition the stock into the numbers of females-atlength. These values were combined with year-specific values of the proportion mature females-at-length, predicted from a model that used capelin stock biomass to represent the year effect on growth (Marshall et al., 2000), to estimate the numbers of mature females at length. A general fecundity model was developed using observations made during a time period when the condition of cod was changing rapidly due to the collapse and subsequent recovery of the Barents Sea capelin stock (Kjesbu et al., 1998). This model was used to hindcast year-specific values of fecundity-atlength. The stock-recruit relationship having TEP as the independent variable shows a different pattern of variation than the biomass-based indices partly because the high recruitment years of 1963, 1964 and 1970 are associated with moderate values of TEP observed in these years (Fig. 6c). The low recruitment observed in the 1980s was associated with TEP values less than $1 \times 10^{14}$.

A bioenergetic index corresponding to the total lipid energy contained in the livers of mature females in the stock has also been developed (Marshall et al., 2000) to take advantage of the long-term database on liver condition index (Yaragina and Marshall, 2000). The liver biomass of mature females ( $\mathrm{g}$ ) was estimated as the product of the numbers of mature females at length (estimated as for TEP), female-only weight-atlength and the length-specific value of the liver condition index. This value was then multiplied by the liver energy content ( $\mathrm{kJ}$ per $\mathrm{g}$ ) that is also derived from the liver condition index (Lambert and Dutil, 1997) to give total lipid energy in kJ. Total lipid energy and recruitment were both low in the late-1980s and early-1990s and the highest observed recruitment (1970) was asso- ciated with total lipid energy in the upper 5 th percentile of the time series (Fig. 6d).

Ichthyoplankton surveys of Norwegian and Barents Sea conducted between 1959 and 1993 (Mukhina et al., 2003) provide a survey-based index of reproductive potential. The only index currently available for the entire survey time period expresses the mean egg abundance averaged across stations, depth strata and developmental stages (Mukhina et al., 2003). This index shows that recruitment is impaired when relative egg abundance is low (Fig. 6e). Variation in recruitment increases with increasing relative egg abundance index and the maximum recruitment observed in 1970 corresponds to the second highest value in the time series.

The pattern of scatter in the different stock- and survey-based parameterizations of the stock-recruit relationship (Fig. 6a-e) was suggestive of non-constant variance. Consequently, a gamma model having a loglink function was fit to the data using a generalized linear models approach. This model assumes an exponential form to the stock-recruit relationship (i.e. Recruitment $\left.=e^{a+b(\text { ReproPot })}\right)$, allows for errors to be nonnormally distributed and specifies that the variability of the response variable increases with increasing mean value of the predictor. Model fit was assessed using the proportion of explained deviance (PED) as well as probabilities based on a $F$ distribution of the test statistic. Recruitment was not significantly correlated with either of the SSB estimates (PED $=0.02$, d.f. $=51, P=$ 0.45 for SSB with year-specific weights and maturities and PED $=0.06$, d.f. $=50, P=0.26$ for SSB with constant values prior to 1981). Model fit was poor for both of these indices because variability in recruitment was highest at low levels of SSB, a property that is inconsistent with the assumption of the gamma model. Both TEP $(\mathrm{PED}=0.13$, d.f. $=51, P=0.09)$ and total lipid energy $(\mathrm{PED}=0.14$, d.f. $=50, P=0.07)$ had higher values of PED but were just above the $\mathrm{P}=0.05$ significance level. The correlation between relative egg abundance and recruitment was statistically significant (PED $=0.40$, d.f. $=30, P<0.01)$. The increase in explanatory power going from the stock-based indices to the survey-based index suggests that the transition between potential and realized TEP could mark a critical stage in the development of year-class strength (Mukhina et al., 2003).

In future, the estimates of TEP and total lipid energy will be refined using improved age/length keys, female-only maturity ogives and new software devel- 
oped for computing TEP (ICES ACFM, MS 2003d). The Russian ichthyoplankton survey time series could also be used to generate indices of realized TEP that would be useful in assessing the accuracy of the stock-based indices.

Incorporating this information into stock management. At the present time, the alternative indices are not being used formally for stock management. However, the most recent assessment estimated the difference between female-only SSB and conventional SSB for a limited time period (1985-2001) using both Russian and Norwegian databases (ICES ACFM, MS 2003c). Both the Russian and Norwegian estimates show a strong tendency for female-only SSB to be less than half of the SSB. Females made an especially low contribution ( $\mathrm{ca} 25 \%$ ) in the years 1987 to 1989 and low proportions were also observed in 1994, 1995, 2000 and 2001. Thus, SSB overestimates the reproductive potential of the stock in those years by a considerable margin. The error is systematic in that it is driven by temporal changes in the age composition of the stock.

Introducing an alternative index of reproductive potential (e.g. female-only SSB or TEP) to stock management would require the development of alternative reference points. In principle, a limit reference point could be defined using the same methodology (segmented regression; ICES ACFM, 2003a, b) that was used to obtain the newly-proposed $B_{l i m}$ value. Implementation of alternative reference points in mediumterm stock projections would require some means of projecting future values. There is a significant correlation between fecundity of cod and capelin stock biomass (Fig. 7) that is analogous to the relationship observed for Baltic cod and herring (Fig. 2). Consequently, fecundity in the upcoming year could potentially be predicted from the projections of capelin stock biomass that are now being provided annually to the AFWG (ICES ACFM, MS 2001b, c; ICES ACFM, MS 2002a) and used to forecast TEP.

\section{Scotian Shelf haddock}

Current management protocol. Two haddock (Melanogrammus aeglefinnus) stocks are found on the Scotian Shelf: the eastern Scotian Shelf haddock (NAFO Div. 4TVW) and southwestern Scotian Shelf haddock (NAFO Div. 4X). The Div. 4TVW haddock stock experienced a collapse in stock abundance in the early-1990s and since 1993 the stock has been closed to all fishing with the exception of a regulated by-catch in the silver hake (Merluccius bilinearis) fishery (Frank et al., MS 1997). Reference points have not been used for management of the Div. 4TVW haddock fishery.

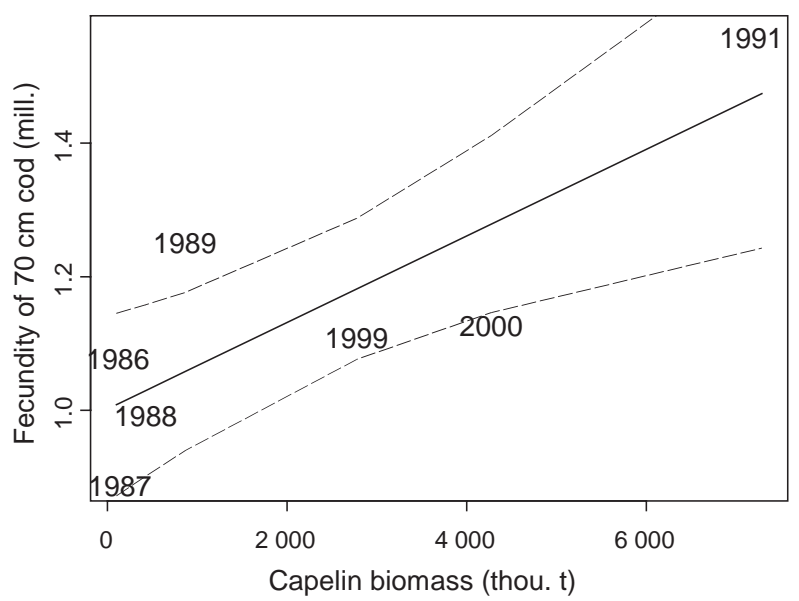

Fig. 7. The relationship between capelin stock biomass and the fecundity of a $70 \mathrm{~cm}$ Northeast Arctic cod. Fecundity relationships for 1986-89 and 1991 are from Kjesbu et al., (1998). Fecundity data for 1999 and 2000 are courtesy of A. Thorsen and O. S. Kjesbu (Institute of Marine Research, Bergen, Norway). Observations are labeled by year. A simple linear regression line is shown as the solid line $\left(r^{2}=0.66, P\right.$ $=0.02$ ) along with $95 \%$ confidence intervals.

The Div. 4X haddock stock is managed through spawning area closures and catch quotas (Hurley et al., MS 1998). Management uses $F_{0.1}=0.25$ as a harvest control rule (Hurley et al., MS 1998) and there are currently no biomass-based reference points for this stock.

Estimating of stock reproductive potential. Fecundity determinations were made from 1997 to 1999 for Div. 4TVW haddock (Blanchard, MS 2000). Using these data, a general fecundity model was developed using both length and condition as independent variables. Both the liver condition index and Fulton's $k$ were evaluated as terms to represent the condition effect. Liver condition explained an additional $20 \%(n=$ 213, $P<0.001)$ of the variation in fecundity-at-length, however, due to the absence of historical liver weight data the model could not be applied retrospectively. Fulton's $k$ explained an additional 15\% $(n=401$, $P<0.001)$ of the variation in fecundity-at-length and was used to represent the year effect in the general fecundity model. The TEP was calculated for 1979-99 using survey-based estimates of numbers-at-length, a 1:1 sex ratio, annual maturity ogives and the aforementioned fecundity model (Blanchard, MS 2000). The correlation between TEP and recruitment (defined as the average number of individuals observed at ages 1 and 2 from the July surveys) was not significant ( $r=0.01$, $n=21, P>0.05)$. Likewise, the relationship between 
SSB (defined as the biomass of ages 3 and older) and recruitment was not significant $(r=-0.05, n=21$, $P>0.05)$.

Condition indices derived from weight/length data are potentially a useful proxy for reproductive potential given that positive correlations with recruitment have been noted previously (Marshall and Frank, 1999). Therefore, the predicted weight at $45 \mathrm{~cm}$ was estimated for both Div. 4TVW and Div. 4X haddock using available survey data. For Div. 4TVW haddock mean annual pre-spawning condition (measured in March) and recruitment were not significantly correlated $(r=0.03$, $P>0.05, n=20)$. However, the correlation became significant when the strong 1999 year-class was deleted ( $r=0.57, P<0.05, n=19$; Fig. 8a). The condition index calculated for the July survey in the year preceding spawning was uncorrelated with recruitment either with ( $r=0.24, P>0.05, n=20)$ or without $(r=0.36, P>0.05$, $n=19$; Fig. $8 \mathrm{~b}$ ) the observation for 1999. A weak, positive correlation between pre-spawning condition (measured in March) and recruitment has previously been reported for the Div. 4X haddock stock (Marshall and Frank, 1999). Updating this relationship was not possible since the spring groundfish surveys have been discontinued. Condition measured in July of the year preceding spawning and recruitment was not significantly correlated with recruitment $(r=0.038, P>0.05$, $n=29$; Fig 8c).

Incorporating this information into stock management. A recent assessment of Div. 4TVW haddock used a traffic light analysis (Caddy, MS 1999) to summarize different indicators of stock status over the time period 1970-2001 (Frank et al., MS 2001). These indicators included information on condition, fecundity and TEP as well as survey abundances, distributional area, SSB, temperature, and exploitation rates. The most recent assessment of Div. 4X haddock included information on condition as a qualitative indicator of stock status (Hurley et al., MS 1998). Given the relatively high degree of interannual variability in condition for both haddock stocks, further evaluation of variability in reproductive potential would be useful.

\section{Striped bass in Chesapeake Bay}

Atlantic striped bass (Morone saxatilis) is a longlived, anadromous species supporting estuarine and coastal fisheries along the east coast of North America. The stock is maintained by recruitment from Chesapeake Bay sub-populations (ASMFC, MS 1998). The recreational and commercial sectors target older (females $>80 \mathrm{~cm}$ ) and younger (young males and imma-
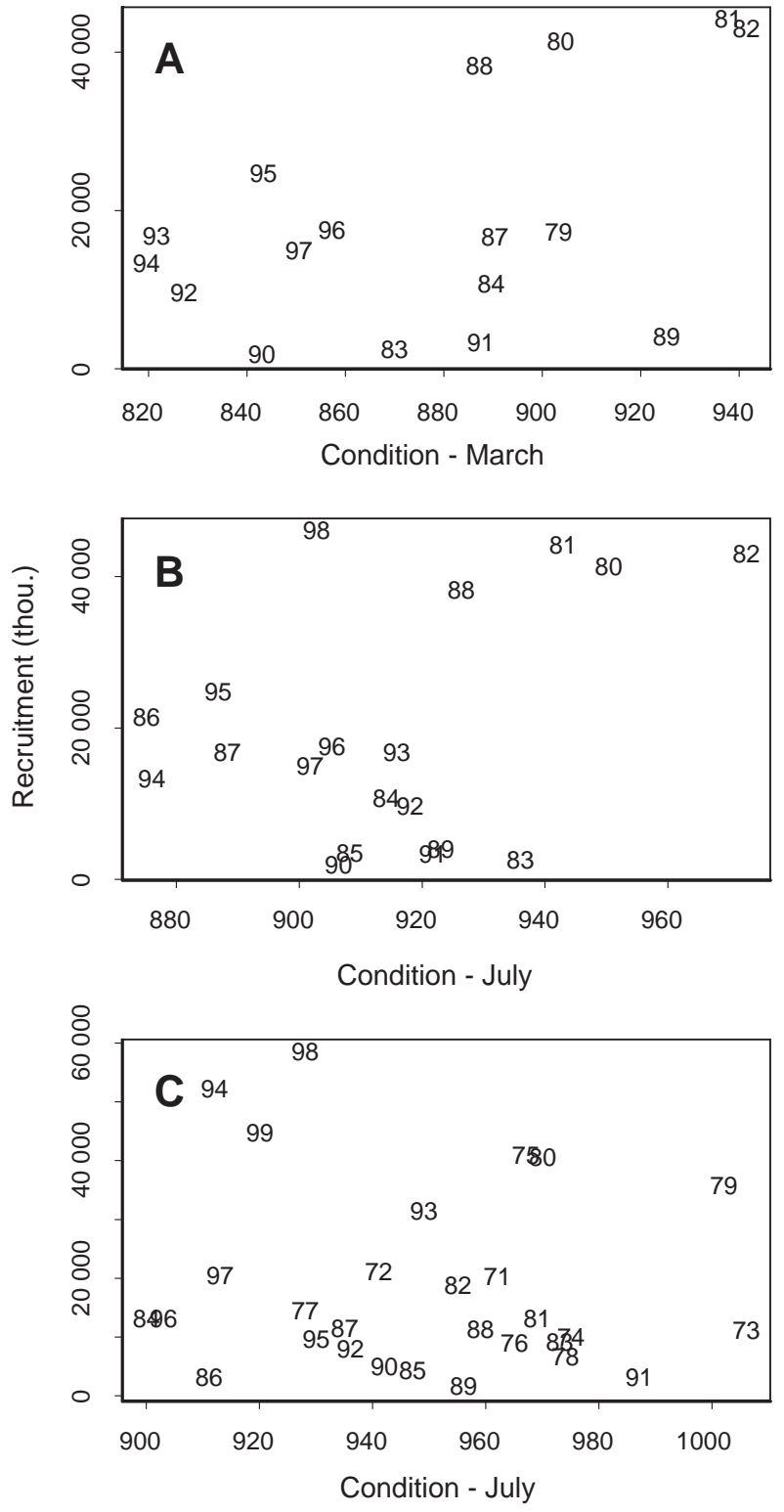

Fig. 8. Relationship between condition (expressed as the predicted weight $(\mathrm{g})$ at $45 \mathrm{~cm})$ and recruitment (defined as the average number, in thousands, by year-class at ages 1 and 2) for Scotian Shelf haddock. a) condition of Div. 4TVW haddock in July of the year preceding spawning; b) condition of Div. 4TVW haddock in March of the spawning year; and c) condition of Div. 4X haddock in July of the year preceding spawning. For Div. 4TVW the outlying observation for 1999 is not shown.

ture females $46-80 \mathrm{~cm}$ ) individuals, respectively. In the late-1970s to early-1980s the targeting of small individuals by the commercial fishery resulted in a stock collapse (Goodyear et al., 1985; Richards and Rago, 1999; Secor, 2000b). Stringent regulations enabled the 
relatively strong 1982 year-class to fully recruit to the spawning population with several strong year-classes following. Thus, striped bass in Chesapeake Bay is an example of a stock that has been successfully rebuilt through effective and timely management measures (Field, 1997).

Current management protocol. Spawner abundances are monitored for major sub-populations and used to tune the VPA. Recruitment is measured by a young-of-the-year juvenile index (1957-present) for several nursery habitats throughout Chesapeake Bay (Goodyear, 1985). The stock-recruit relationship for striped bass can be fit using either a Ricker model (Crecco, MS 2001) or a Beverton-Holt model (G. Shepherd, National Marine Fisheries Service, Woods Hole, MA, pers. comm.). There are no biomass reference points, however, the stock-recruit relationship shows clear evidence of impaired recruitment at low levels of SSB (Fig. 9). The current threshold reference point for $F\left(F_{M S Y}=0.38\right)$ is based on a Shepherd stock-recruit model and a Thompson-Bell Y/R model (ASMFC, MS 1998). The effects of varying exploitation rates are evaluated under the constraint of maximizing recruitment per spawner.

Estimating stock reproductive potential. A proxy for reproductive potential was constructed by estimating the fecundity-weighted age diversity $\left(H_{o b s}\right)$ for three

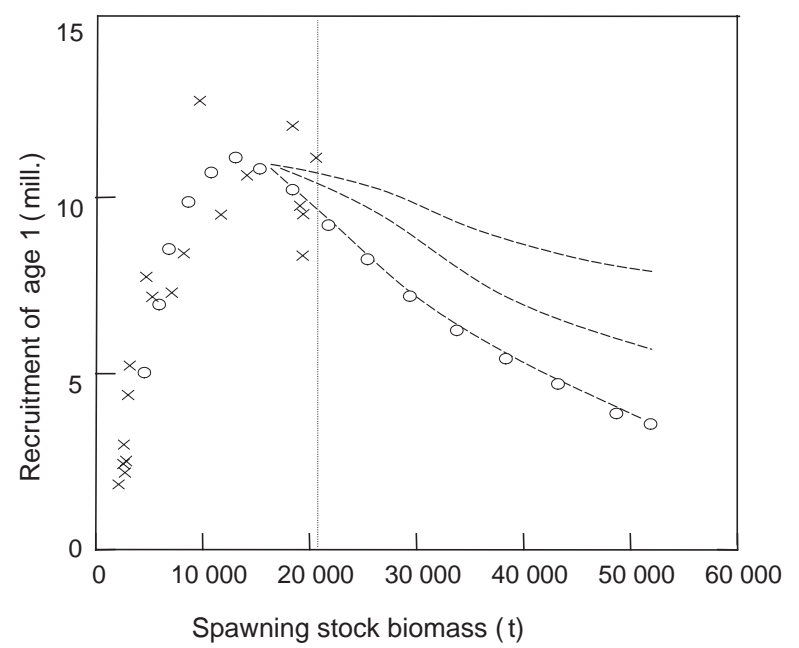

Fig. 9. The stock-recruit relationship for U.S. Atlantic striped bass (1982-2000). The vertical line indicates the boundary between regions with and without observations. Data from virtual population analysis (ASMFC, MS 2001) are shown as crosses. Values from a Ricker model fit by Crecco (MS 2001) are shown as circles. Dashed lines are alternate extrapolations of the Ricker model. sub-populations (Choptank River, Potomac River, and Upper Bay) for the time period 1985-2000 as:

$$
H_{\text {obs }}=\sum q_{t} \times \log _{2} q_{t}
$$

where $q_{t}$, the proportional egg production at age $t$, is estimated as:

$$
q_{t}=C P U E_{f t}\left(\sum_{t=5}^{K} C P U E_{f t}\right)
$$

and where $C P U E_{f t}$ is estimated as $C P U E_{t} \times m t$ with $m t$ representing the fecundity schedule and $\mathrm{K}$ corresponds to the maximum age (35 years). Fecundity schedules were fit for two separate age stanzas (Secor, 2000a). Adjustments were made to the $C P U E_{f t}$ values for gear efficiency and to age estimates for discrepancies resulting from the use of scales (Secor et al., 1995). Consequently, the values of $H_{o b s}$ reported here differ slightly from those given in Secor (2000a).

To provide a benchmark against which $H_{o b s}$ could be judged the fecundity-weighted age diversity of an unexploited population $\left(H_{\max }\right)$ was estimated as:

$$
H_{\text {max }}=-\sum p_{t} \times \log _{2} p_{t}
$$

where $p_{t}$, the proportional egg production at age $t$, is estimated as:

$$
p_{t}=R_{t}\left(\sum_{t=5}^{K} R_{t}\right)
$$

and where $o_{t}$ is the reproductive rate at age $t\left(o_{t}=l_{t} \times\right.$ $m t$ ) with $l_{t}$ being the survivorship schedule for an unexploited population of striped bass (Vetter, 1988). In an unexploited population the proportional egg production by age $\left(p_{t}\right)$ reaches a maximum at age 8 and then declines (Fig. 10). The proportional egg production by age $\left(q_{t}\right)$ for the Potomac River sub-population in 1998 is similar to the $p t$ for an unexploited population, whereas, the values of $q_{t}$ for 1989 are highly skewed towards younger ages (Fig. 10). The degree of similarity between fecundity-weighted age diversity in exploited and unexploited stocks $\left(\% H_{\max }\right)$ was then estimated for each year and sub-population as the ratio of $H_{o b s}$ to $H_{\max }$. The $\% H_{\max }$ provides ancillary information that is specific to population resiliency. The index is similar to egg production per recruit (EPR) indices (Boreman, 1997).

In the Potomac River and Upper Bay subpopulations, $\% H_{\max }$ varied between 31 and $95 \%$ during the period of collapse and recovery (Fig. 11). The 


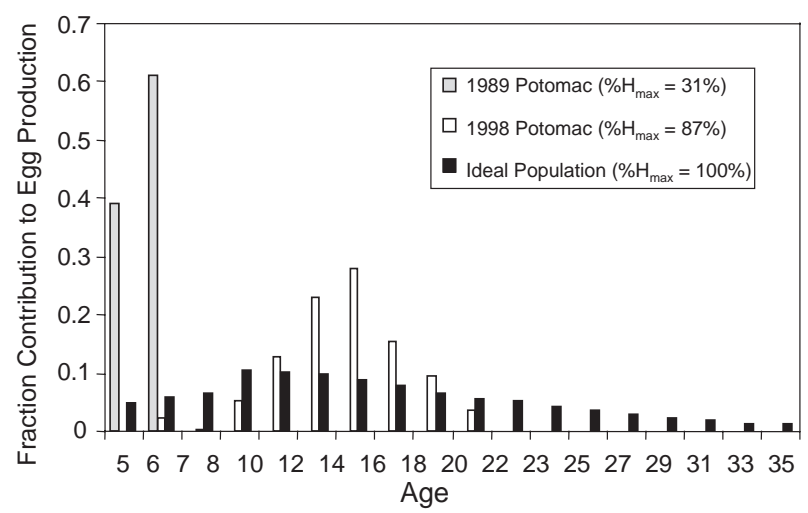

Fig. 10. Comparison of the proportional egg production by age in an unexploited (ideal) striped bass population and the observed proportional egg production by age for the Potomac River stock in 1989 and 1998.

Choptank River sub-population showed less variation, ranging between 60 and nearly $100 \%$. In 1985 and 1986 SSB was low in all three sub-populations, however, $\% H_{\max }$ was high (Fig. 11) due to the presence of older age-classes. From 1987 to 1989 the strong 1982 yearclass dominated the age structure of spawners, lowering the value of $\% H_{\max }$. Furthermore, the contribution from age-classes older than 20 years decreased during this time period (Secor, 2000b).

Maximum recruitment in the Choptank River was consistently associated with high spawning stock abundances. However, under some circumstances fecundity-weighted age diversity could influence recruitment independently of SSB. For example, in Upper Bay (Fig. 12) there were several $>50 \%$ percentile recruitment years that were well below median spawning stock size but for which $\% H_{\max }$ exceeded $50 \%$. This suggests that there is spatial variation in how age structure impacts the reproductive potential of the subpopulations.

Additional evidence of the role of reproductive potential in recruitment dynamics of striped bass is provided by ichthyoplankton surveys of Chesapeake Bay. The proportion of tows in which striped bass eggs were caught has been used as a proxy for reproductive potential (Uphoff, 1993; 1997). Recruitment is correlated with the proportion of tows with eggs for the Choptank River sub-population $(n=11, r=0.45$, for the years sampled between 1985-2000; J. Uphoff, MD Department of Natural Resources, pers. comm.). Pooling information across sub-populations suggested that strong year-classes were only produced in those years

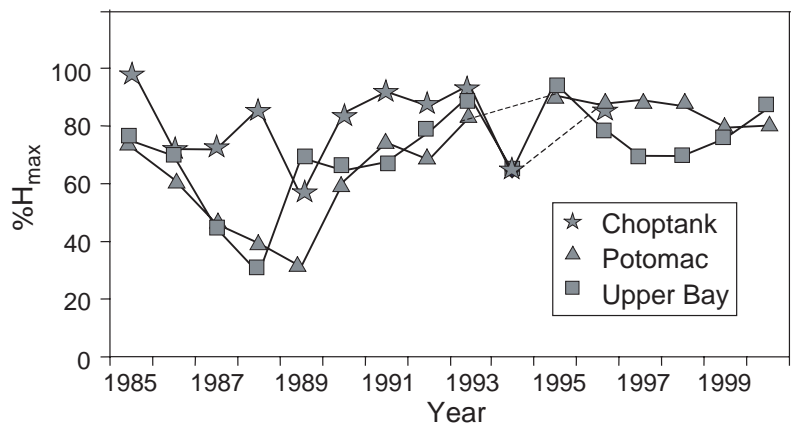

Fig. 11. Time trends in $\% H_{\max }$ for three Chesapeake Bay striped bass spawning stocks (Choptank and Potomac Rivers and Upper Bay), as monitored by the Maryland Department of Natural Resources (MD DNR, MS 2001).

for which egg presence/absence ratio was higher than $60 \%$ (Uphoff, 1997).

Incorporating this information into stock management. The alternative indices of reproductive potential are not used in management, however, developing alternative indices of reproductive potential has highlighted limitations in current knowledge. The fecundity schedules are poorly known and estimates of $p_{t}$ and $q_{t}$ were obtained from a North Carolina population (Olsen and Rulifson, 1992). Research is now underway to model age-specific fecundity in the Chesapeake Bay (R.A. Richards, National Marine Fisheries Center, Woods Hole, pers comm.). Estimates of reproductive rate schedules deviate substantially among researchers depending on whether scales or otoliths are used to age striped bass. In large/old fish, the annuli in scales form at non-annual rates (Secor et al., 1995), however, assessments still rely on scalebased ages. Consequently, the striped bass stock is likely to be comprised of individuals that are substantially older than is currently recognised in the assessment. This longevity may be critical in conferring population resiliency.

\section{American plaice}

Current management protocol. The American plaice (Hippoglossoides platessoides) stock in NAFO Div. 3LNO has been under moratorium since 1995. In 1998, a preliminary $B_{l i m}$ value was proposed based on analysis of the stock-recruit relationship (NAFO MS 1998). The SSB values used in the stock-recruit relationship were derived from a VPA from the early-1990s and used a knife-edge (9+) age at maturity. The 


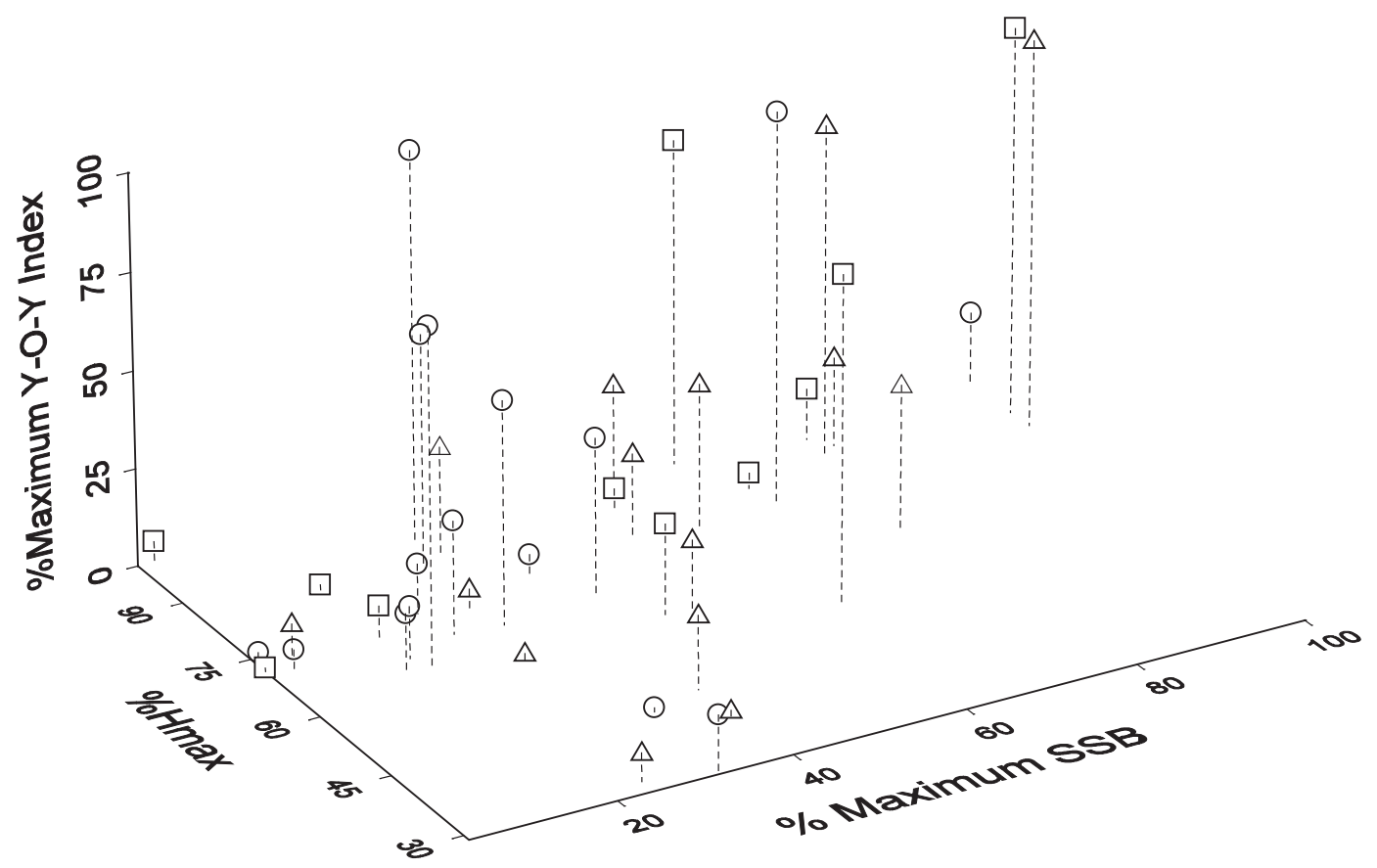

Fig. 12. Recruitment index of young-of-the-year (Y-O-Y) striped bass versus SSB and $\% H_{\max }$ for Choptank (square), Potomac River (triangle) and Upper Bay (circle) systems. Measures of recruitment and SSB are expressed as \% of maximum values for period 1985-2000. SSB and striped bass recruitment are from Maryland Department of Natural Resources fishery independent assessments of each system (MD DNR, MS 2001).

knife-edge maturity ogive overestimated SSB in the early part of the time series and it was later determined that this preliminary $B_{l i m}$ was too high (Morgan et al., MS 1999). A recent assessment of this stock (Morgan et al., MS 2001) used annual estimates of weight-atage and estimates of maturity-at-age by cohort to estimate SSB resulting in a new stock-recruit relationship (Fig. 13). Various stock-recruit models were evaluated but all were found to over-estimate recruitment in recent years. Although poor recruitment is observed below a SSB of 50000 tons, this value was not accepted as a $B_{\text {lim }}$ because of time trends in the recruitment data (NAFO, MS 2001).

Estimating stock reproductive potential. A Beverton-Holt stock-recruit model was fit to the SSB and recruitment data using maximum likelihood. The residuals were then plotted against: a) the weighted mean age of the SSB; b) the proportion of first-time spawners; and c) the proportion of female spawners. The proportion of first-time spawners $\left(P_{f}\right)$ was calculated as:

$$
P_{f}=\frac{\sum_{a=b}^{n} B_{a} P_{a} P f i L s t_{a}}{\sum_{a=b}^{n} B_{a} P_{a}}
$$

where $B_{a}$ is the biomass-at-age from the VPA, $P_{a}$ is the female proportion mature-at-age, $P_{f a}$ is the proportion of first-time spawners at age estimated for individual cohorts, and $b$ and $n$ are the first and last ages (5 and $15+$, respectively). For example, if $10 \%$ of the fish in a given cohort are mature at age 4 and $20 \%$ are mature at age 5 then one-half of the mature age 5 fish are firsttime spawners.

The Beverton-Holt model tends to over-estimate recruitment from 1986-92, particularly relative to the years prior to 1986 (Fig. 13). There is a positive relationship between the residuals from the stock-recruit model and the weighted mean age of the SSB ( $r=0.55$, $\mathrm{df}=35, P<0.001$, Fig. 14a). There was no significant relationship with the proportion of female spawners 


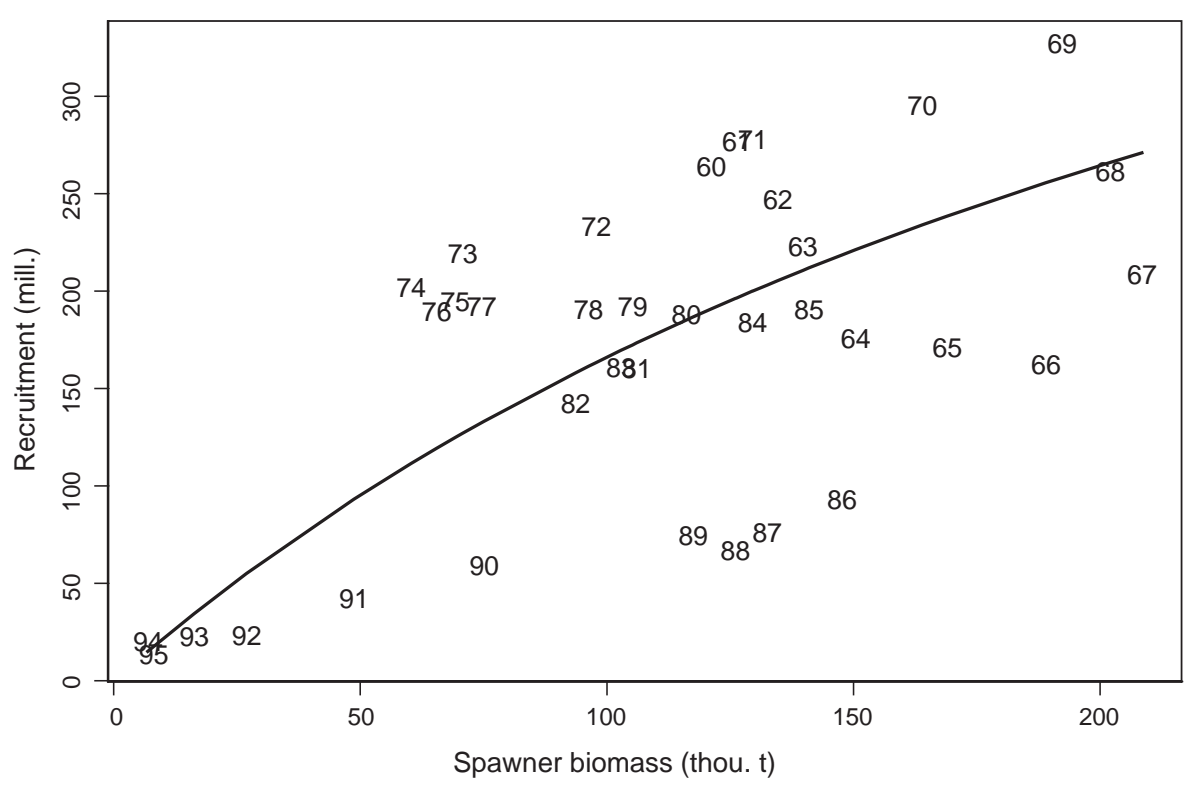

Fig. 13. The stock-recruit relationship for American plaice in NAFO Div. 3LNO showing observed (symbols) and recruitment to age 5 predicted from a Beverton-Holt stock-recruit model (line). Observations are labeled by year-class.

$(r=0.36, \mathrm{df}=19, \mathrm{NS}$, Fig. $14 \mathrm{~b})$ or with the proportion of first-time spawners $(r=-0.07, \mathrm{df}=35, \mathrm{NS}$; Fig. $14 \mathrm{c})$. These results indicate that variations in sex ratio and in the proportion of first-time spawners have no effect on recruitment beyond that already accounted for by the stock-recruit relationship. It is notable that the proportion of female spawners is considerably less than half and in several years is less than 0.2 (Fig. 14c).

Incorporating this information into stock management. Some progress has already been made in the sense that SSB is now calculated using estimates of maturity-at-age rather than using a knife-edge maturity-at-age. The stock-recruit relationship could potentially be improved by including information on weighted mean age of the SSB either by adjusting the estimate of SSB or by including a term for weighted mean age as an extra parameter in the stock-recruit model.

\section{Icelandic cod}

Current management protocol. Management of the Icelandic cod stock uses a harvest control rule that sets the TAC for the next fishing year (beginning September 1) to $25 \%$ of the mean of the available biomass in the beginning of the current calendar year and the beginning of next year with the constraint that the TAC is never less than 155000 tons. Available biomass is defined as the number of age 4 and older at the beginning of the year multiplied by the weight of those age groups in the commercial catch. This biomass is considerably higher than the true biomass because the mean weight-at-age in the catch is higher than in the stock. Stochastic simulations indicated that the $25 \%$ harvest control rule would lead to an average fishing mortality of ages 5 to 10 of 0.4 with less than a $1 \%$ risk of stock collapse where stock collapse was defined as a SSB less than 100000 tons (Jakobsson and Stefánsson, 1998).

The $25 \%$ harvest control rule was first implemented in 1994. Retrospective analyses done in 2000 and 2001 indicated that the stock had been overestimated and that the $25 \%$ harvest control rule had actually been followed only for the first two years (Anon., MS 2001). In the years that followed, the TAC had actually been $27-42 \%$ of the available biomass. Severe reductions in the TAC became necessary and the original $25 \%$ harvest control rule was amended to limit interannual changes in TAC to 30000 tons and the 155000 tons minimum TAC constraint was removed (Anon., MS 2001 ). Although the original $25 \%$ harvest control rule had been accepted by ICES as being in accordance with the precautionary approach, the subsequent amendment was not accepted (Anon., MS 2001).

Biological reference points have been proposed for this stock (Anon., MS 1998) but not adopted. Below-median recruitment occurs more frequently when $\mathrm{SSB}$ is below the long-term median 500000 tons (Fig. 

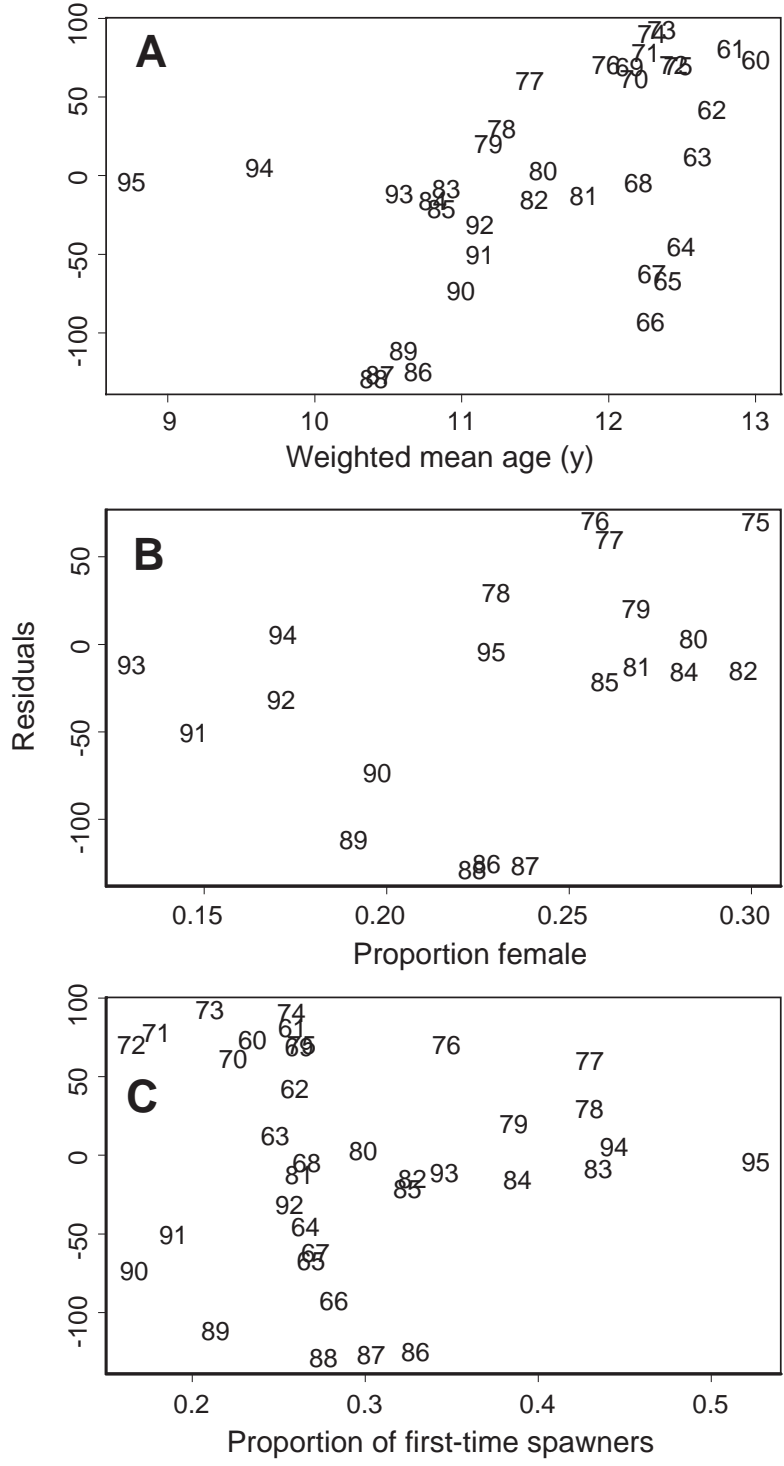

Fig. 14. Residuals from Beverton-Holt stock-recruit model for American plaice in Div. 3LNO plotted against potential proxies of reproductive potential. a) weighted mean age of the SSB, b) proportion of adults that are female and c) proportion of firsttime spawners. Observations are labeled by yearclass.

15). The proposed $B_{p a}$ (300000 tons) was based on the observation that the five weakest year-classes in the time period 1955-94 were generated in years having SSB values less than 300000 tons (Fig. 15). The proposed $B_{\text {lim }}$ value corresponds to the lowest observed SSB (200 000 tons).

Estimating stock reproductive potential. The proxy representing age diversity of the mature fish $(H)$ is estimated as:

$$
H=\left(n \log _{10}(n)-\sum_{i=1}^{k} f_{i} \log _{10}\left(f_{i}\right)\right) / n
$$

where $k$ is the number of age groups, $n$ is the total number of mature fish in all age groups, and $f_{i}$ is the number of mature fish in each age group (Marteinsdottir and Thorarinsson, 1998). The $H$ shows a stronger degree of linear correlation with recruitment $\left(r^{2}=0.17, n=43\right.$, Fig. 16) than does $\operatorname{SSB}\left(r^{2}=0.06, n=\right.$ 43, Fig. 15). A positive relationship between $H$ and recruitment is consistent with observations that the size and age composition of spawners has a major impact on the amplitude of potential egg production, time and duration of spawning as well as offspring viability (Scott et al., 1999; Marteinsdottir and Björnson, MS 1999; Marteinsdottir et al., 2000a; Marteinsdottir and Begg, 2002).

In future, historical trends in egg production will be reconstructed from available data sources. Information on length distributions has been collected since the early-1900s. Fecundity determinations have been made intermittently (Joakimsson, MS 1969; Schopka, MS 1971; Marteinsdottir et al., 2000a; Marteinsdottir and Begg, 2002) and a relationship between atresia and female size, spawning stage and condition has recently been established (Hardardottir, MS 2001). Because the Icelandic cod stock consists of multiple spawning aggregations (Marteinsdottir et al., 2000b; Begg and Marteinsdottir, 2000; Begg and Marteinsdottir, 2002) the potential egg production has been estimated for 18 offshore and inshore areas separately (Begg and Marteinsdottir, 2003). Additional data on temporal variation in size and quality of eggs and larvae in relation to female size, age and condition (Marteinsdottir and Steinarsson, 1998; Marteinsdottir and Begg, 2002) will be used to further refine these estimates.

Incorporating this information into stock management. With respect to the management of Icelandic cod, no attempts have been made to incorporate information on age diversity or the influence of maternal size and condition on the timing, quality and amplitude of egg production into management. In recent years, large cod have been specifically targeted by the fishery due to a combination of high price for the cod and high cost of rental quota in the Icelandic quota system. This has led to severe reduction in the abundance of large cod. In coming years most of the spawning stock will be composed of the 1997 or younger year-classes thereby increasing risk of poor recruitment. 


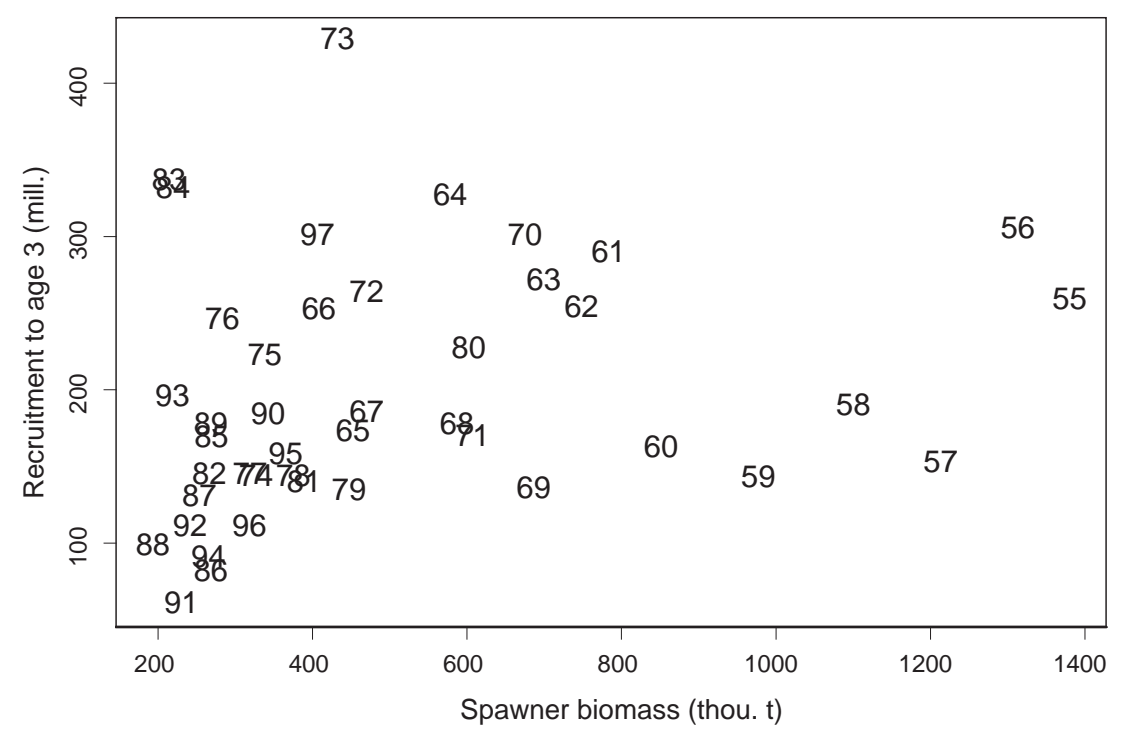

Fig. 15. The scatterplot of SSB versus recruitment for Icelandic cod based on data from the most recent assessment (Anon., MS 2001). Observations are labeled by year-class.

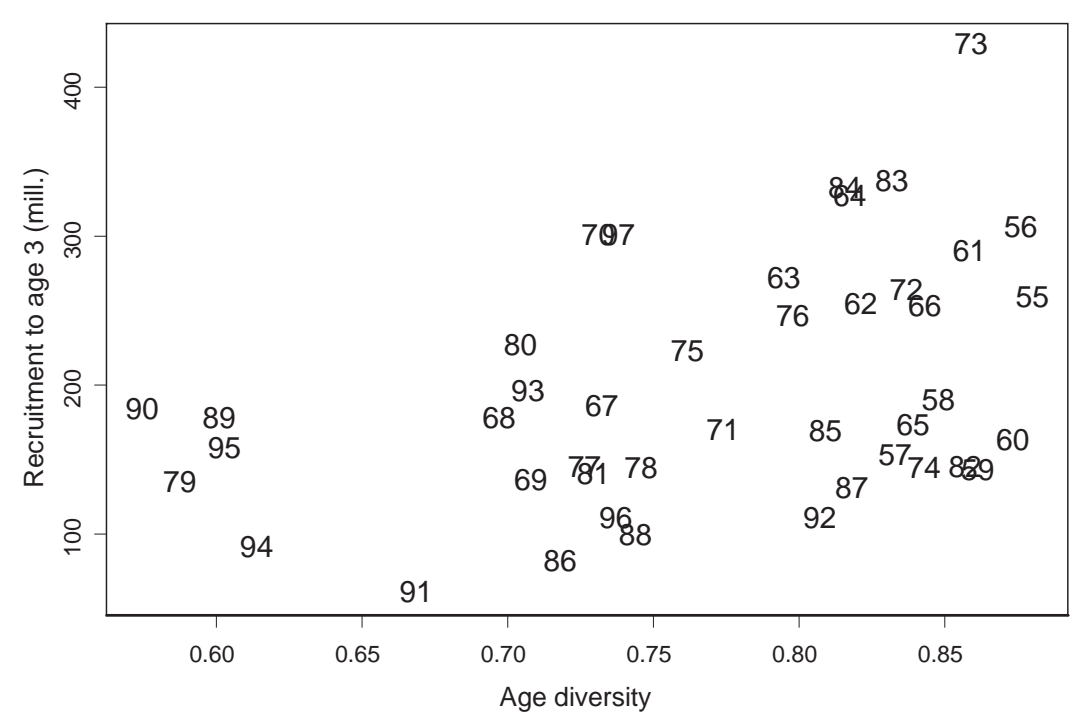

Fig. 16. Relationship between age diversity and recruitment for Icelandic cod (updated from Marteinsdottir and Thorarinsson, 1998). Observations are labeled by year-class.

\section{Georges Bank haddock}

Current management protocol. The Georges Bank haddock stock (NAFO Div. 5Z) is a transboundary resource shared by the USA and Canada. The USA assessment is for the entire stock area, whereas, the Canadian assessment is for NAFO Subdiv. $5 \mathrm{Zj}$ and $5 \mathrm{Zm}$ only. In the USA, Div. $5 Z$ haddock is managed by a target total allowable catch (TTAC) based on $F_{0.1}$. In
Canada, Subdiv. 5Zjm haddock is managed by a TAC, also based on $F_{0.1}$.

The stock-recruit relationship for Georges Bank haddock encompasses a 70-year time period (Fig. 17a). The data show a fan-shaped scatter of points with poor recruitment generally observed at values of SSB less than 75000 tons and higher and more variable recruit- 


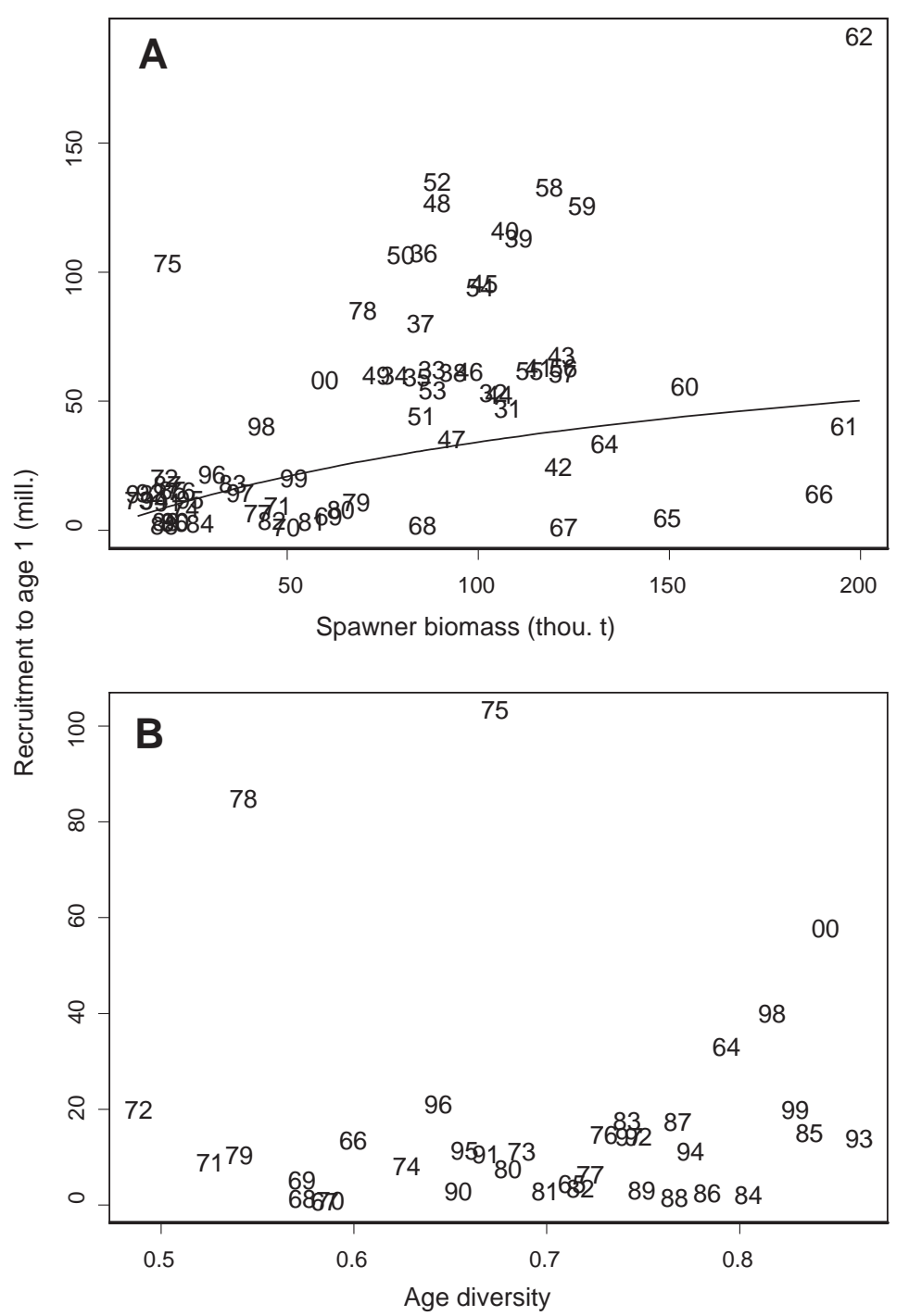

Fig. 17. Relationship between two indices of reproductive potential and recruitment to age 1 for Georges Bank haddock in NAFO Div. 5Z. a) spawner biomass (1931-2000, outlying observation for 1963 omitted); and b) age diversity (1964-2000). Observations are labeled by year-class.

ment observed above that level. A Beverton-Holt model provides the best parametric fit to this data (Fig. 17a), however, because of a non-stationary pattern in the residuals the model parameters were not accepted and a non-parametric approach was used to obtain the $B_{M S Y}$ estimate (NEFSC, MS 2002). $B_{M S Y}$ was estimated to be 250300 tons at $F 40 \%$ of maximum spawning potential. For the stochastic age-based projections of spawning stock biomass and catch, recruitment is modelled by re-sampling observed recruitments from SSB greater than 75000 tons.
Estimating stock reproductive potential. Data from the most recent analytical assessment (R. Brown, National Marine Fisheries Service, Northeast Fisheries Science Center, Woods Hole, Massachusetts, 02543 USA, pers. comm.) were used to estimate age diversity for the full time series (1963-2000). Linear regression analysis of recruitment and age diversity for the time series did not show a significant relationship, in part because of outlying values of recruitment (Fig. 17b). However, the data indicate a trend towards higher recruitment with higher age diversity particularly during 
1990-2000. This suggests that multivariate models including factors such as age diversity, spawning time, conditions might explain more of the variation in recruitment than the bivariate relationship between SSB and recruitment.

In future, alternative indices of reproductive potential can be developed using egg abundance data that are available from ichthyoplankton surveys conducted under three programs: i) Marine Resource Monitoring Assessment and Prediction (MARMAP) surveys (1977 to 1987); ii) larval herring surveys (1988 to 1994); and iii) Global Ocean Ecosystems Dynamics (GLOBEC) surveys (1995 to 1999). Furthermore, several time series of condition exist including: i) NEFSC bottom trawl surveys conducted during spring and autumn surveys (1992-2002); and ii) Canadian spring surveys which have been conducted since 1986. However, it should be noted that this stock might not exhibit poor condition given the high productivity of Georges Bank and the relatively rapid growth rate of the haddock residing there.

Incorporating this information into stock management. Currently, management is based strictly on status determinations of SSB and F. Ancillary information about the stock such as condition or age structure of the stock could be considered. If future analyses of data provide a quantitative change in the perception of the stock-recruit relationship then the current MSY reference points would need to be reconsidered. However, reference points that are not based on MSY would be difficult to implement in the U.S.-based fishery given existing legal protocols specified by the Sustainable Fisheries Act (US Department of Commerce, MS 1998).

\section{Flemish Cap cod}

Current management protocol. The Flemish Cap cod stock (NAFO Div. 3M) has been under moratoria since 1999. Its collapse has been attributed to overfishing, an increase in catchability and a sustained period of poor recruitment (Vázquez et al., MS 1999). The most recent assessment indicated that SSB is currently at a historical low and that since 1992 recruitment has been at or near the historical low (Vázquez and Cerviño, MS 2001). Substantial changes in the structure of the spawning stock have occurred such that from 1978 to 1985 the oldest age-class observed in the stock ranged between 13 and 19 years, whereas, from 1995 to 1999 it was between 7 and 10 years. In addition, considerable reductions in age- and size-atmaturity were observed in the first half of 1990 s (Saborido-Rey and Junquera, 1998).
Although the fishery is closed for the foreseeable future, biomass reference points have nevertheless been developed. The stock-recruit relationship (Fig. 18a) was the basis for establishing a $B_{\text {lim }}$ value of 14 000 tons (NAFO, MS 2000).

Estimating stock reproductive potential. The most recent assessment (Vázquez and Cerviño, MS 2001) used knife-edge maturity-at-age from 1972 to 1990 and average values of catch weight at age from 1972 to 1987 to estimate SSB. The stock-recruit relationship shows recruitment values to peak at intermediate values of SSB (Fig. 18a). It was possible to refine the SSB estimates from 1978 to 1985 by replacing the constant weight- and proportion mature-at-age with observed values from Canadian surveys. The proportion of mature at age for 1986 and 1987 was estimated as the mean for adjacent years (1985 and 1988) for each age. This resulted in the SSB values for 1984 and 1985 shifting towards higher values that were more consistent with observed levels of recruitment (Fig. 18c). Incorporating sex ratio information to estimate the femaleonly SSB did not alter the pattern of variability substantially (Fig. 18e).

The residuals from fitting a non-linear model to the stock-recruit relationship were estimated for each of the three formulations of SSB. Residuals for SSB values estimated using fixed values for the weights and maturities (Fig. 18a) show a significant positive relationship with the age diversity index $\left(r^{2}=0.18\right.$, $P=0.04$; Fig. 18b). The residuals calculated using SSB estimated with year-specific weights and maturities was not significant $\left(r^{2}=0.11, P=0.12\right.$; Fig. $\left.18 \mathrm{~d}\right)$ while the relationship estimated using female-only SSB was nearly signficant $\left(r^{2}=0.16, P=0.06\right.$; Fig. 18f). Thus, the analysis of residuals suggests that the reproductive and recruitment potential of the stock is enhanced by the presence of older individuals.

Additional data are available for refining estimates of reproductive potential in the future. Condition, ovary weight and liver weight are available from Canadian surveys conducted from 1978 to 1985 . Since 1988 condition and ovary weights have been measured during EU surveys conducted in the summer, however, the timing of this survey (post-spawning period) is problematic for obtaining data that are suitable for estimating reproductive potential.

Incorporating this information into stock management. Progress towards this goal has been made given that SSB is now calculated using yearspecific values of maturity-at-age rather than using 

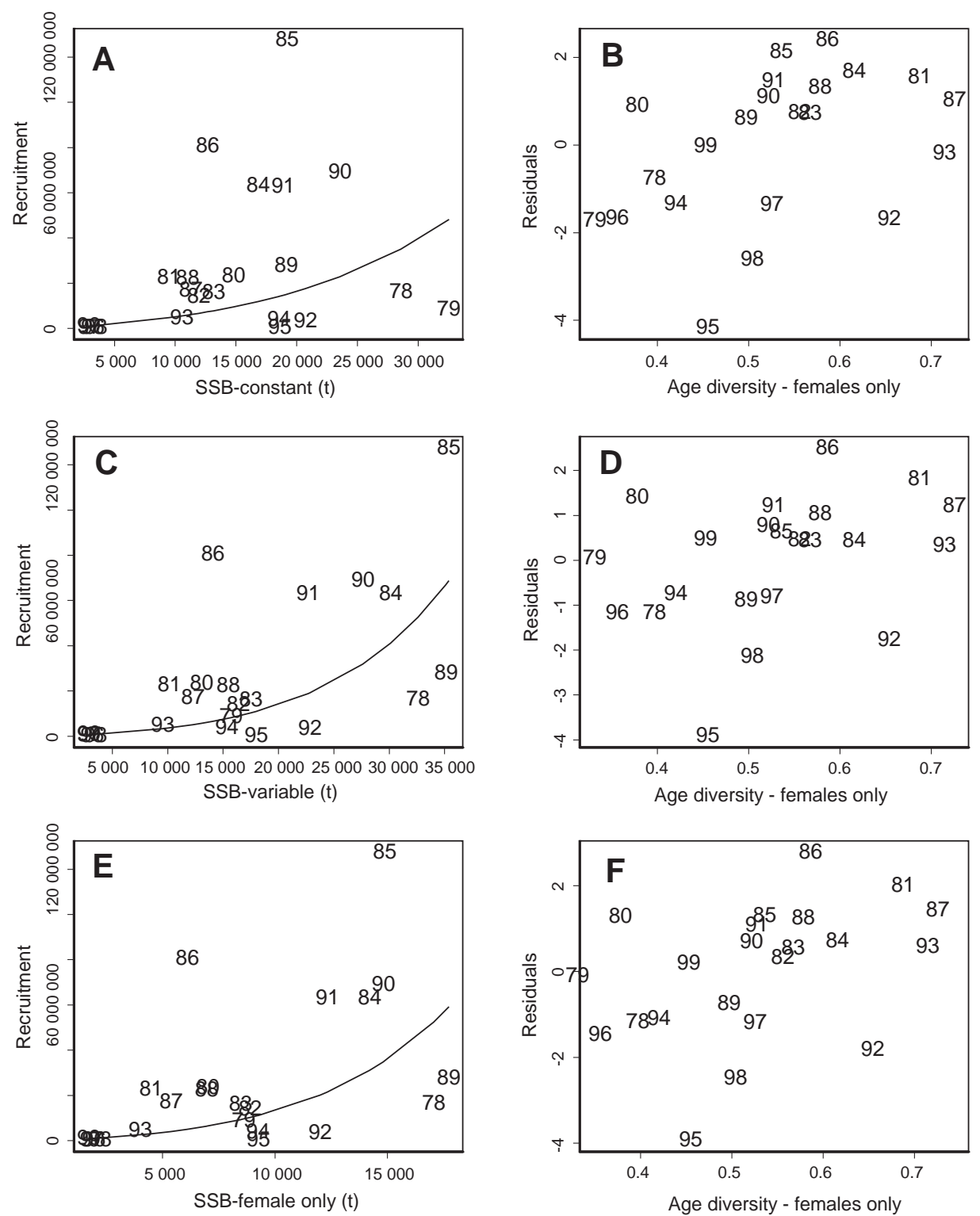

Fig. 18. Panels on the left show different parameterizations of the stock-recruit relationship for Flemish Cap cod. Panels on the right show the residuals from a non-linear model (shown in the left-hand panels as a solid line) plotted against age diversity. a) SSB estimated using constant maturity and weight, b) residuals from a) plotted against age diversity, c) SSB estimated using year-specific maturity and weight, d) residuals from c) plotted against age diversity, e) female-only SSB, and f) residuals from e) plotted against age diversity.

knife-edge values. Unlike many cod stocks, the biomass-based stock-recruit relationships show clear evidence of impaired recruitment at low levels of SSB (Fig. 18a, c, e). Depending on the estimate of SSB used, age diversity explained a significant or nearly significant portion of the residual variance in the stock-recruit relationship which suggests that the maternal effect on recruitment is not being fully captured by biomass-based measures alone. However, any further evaluation of how long-term changes in spawning structure (both in age diversity and maturity-at-age) have affected the reproductive potential is complicated by serious data limitations or deficiencies. The time series for condition is discontinuous with respect to spawning stage at which the weight measurements were taken (February for Canadian surveys, summer for EU 
surveys). Some fecundity data are available for 1979 and 1982-85 (G. Lilly, Science Branch, Dept. of Fisheries and Oceans, Canada, unpub.data). However, collecting new data is difficult given both the timing of the annual survey (post-spawning period) and the present moratorium on fishing.

\section{Discussion}

Collectively, the nine case studies illustrate how the collation of historical data and acquisition of new information on fecundity can be used to develop alternative indices of stock reproductive potential. Incorporating maternal effects on egg viability is the obvious next step in developing indices that more closely approximate the realized TEP of a stock (e.g. Solemdal, 1997; Vallin and Nissling, 2000; Murawski et al., 2001). Further refinements can be expected in the near future given the number of research projects undertaking experimental, field and modelling studies on reproduction and recruitment (Table 3). Serious consideration of such indices by fisheries management is warranted, given the tractable nature of reproductive biology and its clear import for recruitment (Marteinsdottir and Begg, 2002).

There were no examples among the case studies of the alternative indices influencing management advice either directly or indirectly. Close scrutiny of the relationship between SSB and TEP is the first step in determining whether fundamental changes to current management protocols are necessary (Marshall et al., 1998). As several of the case studies illustrated, it is possible to model historical trends in fecundity by representing the year-effect with a term, e.g. condition or prey availability, explaining a significant amount of the variability in interannual fecundity (Kjesbu et al., 1998; Blanchard, MS 2000) or relative fecundity (Kraus et al., 2000, 2002). Using such a modelling approach, TEP was estimated for Baltic cod, Northeast Arctic cod, and eastern Scotian Shelf haddock (Fig. 19). The relationships between SSB and TEP were highly variable for all three stocks $\left(r^{2}\right.$ values were $0.80,0.26$ and 0.44 , respectively, for Baltic cod, Northeast Arctic cod, eastern Scotian Shelf haddock). All three relationships showed distinct time trends with relatively rapid shifts towards either higher (Baltic cod since 1994) or lower (Northeast Arctic cod since the 1980s, eastern Scotian Shelf haddock since the 1990s) values of TEP for a given level of SSB (Fig. 19). Thus, the relationship between SSB and TEP is not directly proportional for these stocks. This result alone could justify the application of alternative indices to stock management.
Incorporating an alternative index of reproductive potential in management could also be justified if it explained a higher proportion of recruitment variability compared to SSB. This was not the case for eastern Scotian Shelf haddock; neither SSB nor TEP were significantly correlated with recruitment. However, the incorporation of more highly resolved biological data in the stock-based index of potential TEP increased the correlation with the survey-based index of daily egg production for Baltic cod that was used as a proxy of realized TEP (Köster et al., 2003). The stock-based index that was most highly correlated with realized TEP was included in a recruitment model that also included variables representing environmental effects on survival (Fig. 5). For Northeast Arctic cod, the proportion of explained deviance in recruitment was higher for TEP than for SSB but the correlation was still not significant. Given that an analysis of abundance estimates for early life history stages identified at least two critical stages at which recruitment undergoes substantial modification prior to age 3 (Mukhina et al., 2003), the explanatory power of the stock-recruit relationship may be low irrespective of the index used to represent stock reproductive potential.

Alternative parameterizations of the stock-recruit relationship might be better for identifying levels of reproductive potential at which recruitment is impaired, a property that is critical for defining limit biomass reference points (ICES ACFM, MS 2002b). For example, many stock-recruit relationships contain observations having low or intermediate values of SSB and relatively high recruitment. Such observations undermine conservation efforts by suggesting that good recruitment can result even when the reproductive potential of stocks is low. The case studies provided several examples of strong year-classes that shifted their position in the stock-recruit relationship from relatively low values of SSB to relatively high values of the alternative index. For example, the 1994 and 1995 year-classes for Baltic cod (Fig. 4), the 1963, 1964, 1969 and 1970 year-classes for Northeast Arctic cod (Fig. 6), and the 1984, 1985 and 1989 for Flemish Cap cod (Fig. 18) shifted from the left-hand side of the stock-recruit plot towards the right-hand side when the alternative indices were used instead of SSB. These shifts improve the ability of the stock-recruit relationship to identify impaired recruitment and help to refute the notion that recruitment is independent of the reproductive potential of a stock.

Developing TEP estimates is often hindered by the lack of fecundity data both on historical and con- 
TABLE 3. A partial selection of recent and ongoing research projects that were relevant to either quantifying reproductive potential at the stock-level or utilizing this information in management.

\begin{tabular}{|c|c|c|c|c|}
\hline Acronym & Title & $\begin{array}{r}\text { Project } \\
\text { period }\end{array}$ & $\begin{array}{r}\text { Funding } \\
\text { agency }\end{array}$ & Participating countries \\
\hline STORE & $\begin{array}{l}\text { Environmental and fisheries } \\
\text { influences on fish stock } \\
\text { recruitment in the Baltic Sea }\end{array}$ & 1999-2002 & EU & $\begin{array}{l}\text { Germany, Denmark, Finland, Sweden, } \\
\text { Estonia, Latvia, Poland, Russia }\end{array}$ \\
\hline STEREO & $\begin{array}{l}\text { An operational model of the } \\
\text { effects of stock structure } \\
\text { and spatio-temporal factors } \\
\text { on recruitment }\end{array}$ & 1999-2002 & EU & $\begin{array}{l}\text { Denmark, Scotland, Norway, Iceland, } \\
\text { Germany }\end{array}$ \\
\hline MACOM & $\begin{array}{l}\text { Demonstration of maternal } \\
\text { effects of Atlantic cod: } \\
\text { combining the use of unique } \\
\text { mesocosm and novel } \\
\text { molecular techniques }\end{array}$ & $2000-2002$ & $\mathrm{EU}$ & Norway, UK, Germany, Denmark \\
\hline GADOLIFE & $\begin{array}{l}\text { Growth dynamics and } \\
\text { regulation of energy } \\
\text { allocation in gadoids of } \\
\text { different life strategies } \\
\text { and in different } \\
\text { environments }\end{array}$ & $2001-2004$ & $\begin{array}{l}\text { Department } \\
\text { of Fisheries } \\
\text { and Oceans }\end{array}$ & Canada \\
\hline METACOD & $\begin{array}{l}\text { The role of sub-stock } \\
\text { structure in the maintenance } \\
\text { of cod meta-populations }\end{array}$ & $2002-2005$ & $\mathrm{EU}$ & Iceland, Scotland, Denmark, Germany \\
\hline RASER & $\begin{array}{l}\text { Reproduction and stock } \\
\text { evaluation for recovery }\end{array}$ & $2002-2005$ & $\mathrm{EU}$ & Norway, UK, Spain \\
\hline
\end{tabular}

temporary time scales (Tomkiewicz et al., 2003). Several published studies have estimated TEP using fecundity models that have been developed for other stocks. Such a practice is inadvisable given that across stocks the fecundity of cod of a given length can vary by more than $100 \%$ (Marteinsdottir and Begg, 2002). Furthermore, it masks the real need for stock-specific data. Closed fisheries and inappropriately timed surveys are serious impediments to routine fecundity monitoring, however, they do not justify failing to collect information on a key life history parameter that has been largely overlooked since the inception of standardized sampling programs (Tomkiewicz et al., 2003). It has been hypothesized that factors affecting growth and reproduction will be critical in rebuilding depleted cod stocks (Rose and O'Driscoll, 2002). Testing this hypothesis will obviously require new data describing the degree of interannual variation in fecundity (Murua et al., 2003). The development of methodology for rapid fecundity determinations (e.g. Thorsen and Kjesbu, 2001) makes routine fecundity monitoring considerably less labour intensive.

In the absence of detailed fecundity information, useful information on reproductive potential can be inferred from basic information about the age, gender and/or size composition of the stock. Age diversity indices showed promise in explaining recruitment levels directly (e.g. Icelandic cod) or in explaining residual variation from the stock-recruit relationship (e.g. striped bass in Chesapeake Bay, Flemish Cap cod). Female-only SSB can also lead to improvements in the stock-recruit relationship (e.g. Baltic cod, Flemish Cap cod). This index is both conceptually appealing and easily estimated from existing data resources. It may also be possible to construct bioenergetic indices of reproductive potential when historical data describing the lipid content of the stock are available (e.g. 

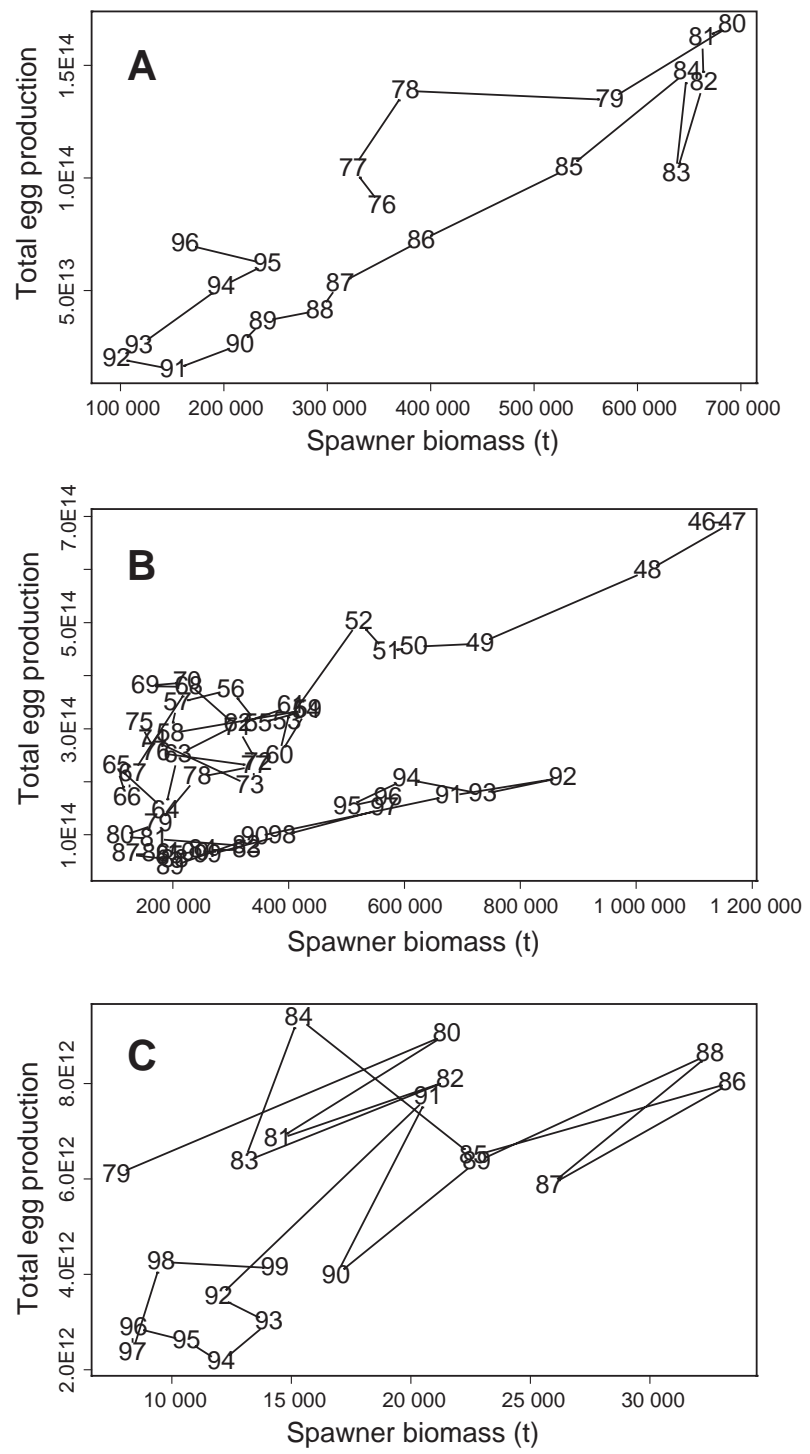

Fig. 19. Relationships between SSB and potential TEP. a) Baltic cod, b) Northeast Arctic cod, and c) eastern Scotian Shelf haddock. Observations are labeled by year and the time trajectory is shown by the solid line.

Northeast Arctic). Such databases are often collected systematically for industrial purposes (Schülein et al., 1995) and constitute a relatively underutilized data source.

Given that all of the case study species are relatively long-lived, it is also worth considering the management implications of a truncated age structure resulting from high fishing mortality. Due to the cyclical nature of marine ecosystems (Stenseth et al., 2002) fish stocks often experience environmental conditions that oscillate between prolonged periods of unfavourable and favourable conditions. Stocks having a high age diversity may be more likely to withstand periods of unfavourable environmental conditions and experience the combination of high reproductive potential and favourable conditions giving rise to strong yearclasses. The resiliency conferred by a broad age structure has been termed the "storage effect" (Chesson, 1994; Secor, 2000a) and it is increasingly regarded as a key attribute for the sustainability of fisheries resources (Fromentin and Fonteneau, 2001; Francis, 2003). High age diversity also results in increased diversity in spawning behaviour. For example, older females spawn often at different times than younger ones (Lambert, 1990; Secor, 2000a). This potentially increases the opportunities to match spawning with favourable conditions for larval survival (Kjesbu et al., 1998). Consequently, to accurately estimate the realized reproductive potential of a stock it may be necessary to collect and/or report information on spawners at finer temporal and spatial scales than are currently used by management (Begg and Marteinsdottir, 2003).

In addition to their practical importance to fisheries management, more precise estimates of TEP are of considerable interest for fisheries research because they allow for estimation of egg mortality rates during early and potentially critical life history stages (Nash, 1998). Similarly, expressing survival rates for individual cohorts as the ratio of recruits to TEP is preferable to the procedure in common use which assumes that SSB is directly proportional to TEP (Barrowman and Myers, 2000). The fecundity data collected in support of TEP estimates will also allow for more highly resolved investigations of the relationships between maximum population growth rates and key life history traits (Hutchings, 1999; Denney et al., 2002). Lastly, fecundity data can help to elucidate trophodynamic linkages between growth (sensu reproductive potential of individuals) and food availability to the stock (e.g. Fig. 2 and 7).

The precautionary approach, as applied to fisheries management, emphasizes incorporating uncertainty wherever knowledge is limiting. However, fisheries management must be equally able to accommodate the obverse situation, i.e. incorporating knowledge when it is available. Alternative indices of reproductive potential were available for the nine stocks included here as case studies. Three comparatively data-rich stocks having time series for TEP provided clear evidence that SSB is not directly proportional to TEP. The remaining case studies showed that properties of the spawning 
stock (e.g. age diversity, condition) can influence recruitment in ways that are not properly accounted for by using SSB as the sole measure of reproductive potential. It is reasonable to expect further progress towards resolving whether SSB is a sufficiently sensitive index of reproductive potential given the number of dedicated studies that are either completed or ongoing (Table 3). Such targeted research will help to develop consensus regarding the nature and scope of changes that will be required of fisheries management. It is already clear that, rather than being constrained to using approaches designed for data-poor situations, management protocols should be sufficiently flexible to accommodate the use of detailed information on reproductive potential whereever it is felt to promote resource sustainability. The direct application of data on reproductive potential to fisheries management would have the corrollary benefit of stimulating the acquisition of information for data-poor stocks, and over time, reducing the large information gradient that currently exists.

\section{Acknowledgements}

The authors thank the following individuals for their assistance: R. Brown, K. T. Frank, E. Hamilton, B. Healey, P. Hurley, O. S. Kjesbu, P. Shelton, G. Shepherd, A. Thorsen, and J. Uphoff. Two anonymous referees are thanked for their helpful comments on an earlier version of the manuscript. Funding from the Research Council of Norway (133836/122) is acknowledged by the first author. E. A Trippel is acknowledged with gratitude for chairing the NAFO Working Group on Reproductive Potential. L. Motos, H. Murua, L. Zaslavskaya, and N. Yaragina facilitated the two meetings of the working group.

\section{References}

AJIAD, A., T. JAKOBSEN, and O. NAKKEN. 1999. Sexual differences in maturation of Northeast Arctic cod. J. Northw. Atl. Fish. Sci., 25: 1-15.

ANON. MS 1998. State of the marine stocks in Icelandic waters 1997/1998. Prospects for the quota year 1998/ 1999. Marine Research Institute Report Series.

MS 2001. State of the marine stocks in Icelandic waters 2000/2001. Prospects for the quota year 2001/2002. Marine Research Institute Report, Series 80.

ASMFC (Atlantic States Marine Fisheries Commission). MS 1998. Source document to Amendment 5 to the Interstate Fishery Management Plan for Atlantic striped bass. Fishery Management Report, No. 34, Washington, D.C., 117 p. + app.

ASMFC (Atlantic States Marine Fisheries Commission) 2001. 2001 Summary Report on the Age-based Assessment of the Atlantic Striped Bass. ASMFC
Striped Bass Technical Committee. September 2001, $32 \mathrm{p}$.

BARROWMAN, N. J., and R. A. MYERS. 2000. Still more spawner-recruitment curves: the hockey stick and its generalizations. Can. J. Fish. Aquat. Sci., 57: 665-676.

BEGG, G. A., and G. MARTEINSDOTTIR. 2000. Spawning origins of pelagic juvenile cod (Gadus morhua) inferred from spatially explicit age distributions: potential influences on year-class strength and recruitment. Mar. Ecol. Prog. Ser., 202: 193-217.

2002. Environmental and stock effects on spawning origins and recruitment of cod Gadus morhua. Mar. Ecol. Prog. Ser., 229: 263-277.

2003. Spatial partitioning of relative fishing mortality and spawning stock biomass of Icelandic cod. Fish. Res., 59: 343-362.

BLANCHARD, J. L. MS 2000. Maternal contribution to the reproductive potential of a recovering fish stock: variability in the fecundity and condition of haddock (Melanogrammus aeglefinus) on the Scotian Shelf. M.Sc. Thesis, Dalhousie University, Halifax, N.S. $110 \mathrm{p}$.

BLEIL, M., and R. OEBERST. MS 1996. The fecundity of cod in ICES Subdivisions 22, 24 and 25 in the years 1992 to 1995 (preliminary results). ICES C.M. Doc., No. 1996/J:8, 22 p.

BOREMAN, J. 1997. Sensitivity of North American sturgeons and paddlefish to fishing mortality. Environ. Biol. Fish., 48: 399-405.

BRODEUR, R. D., S. J. PICQUELLE, D. M. BLOOD, and N. MERATI. 1996. Walleye pollock egg distribution and mortality in the western Gulf of Alaska. Fish. Oceanogr., 5 (Suppl. 1): 92-111.

BRODZIAK, J. K. T., W. J. OVERHOLTZ, and P. J. RAGO. 2001. Does spawning stock affect recruitment of New England groundfish? Can. J. Fish. Aquat. Sci., 58: 306-318.

BROMLEY, P. J., C. RAVIER, and P. R. WITTHAMES. 2000. The influence of feeding regime on sexual maturation, fecundity and atresia in first-time spawning turbot. J. Fish Biol., 56: 264-278.

CADDY, J. F. MS 1999. Deciding on precautionary management measures for a stock based on a suite of limit reference points (LRPs) as a basis for a multiLRP harvest law. NAFO Sci. Coun. Studies, 32: 55-68.

CHESSON, P. L. 1994. The storage effect in stochastic population models. Lecture Notes in Biomathematics, 54: $76-89$.

CORE (Cod Recruitment in the Baltic). MS 1998. Mechanisms influencing long term trend in reproductive success and recruitment of Baltic cod: Implications for fisheries management. Final Report to the EU Commission, AIR 941226.

CRECCO, V. MS 2001. Protected striped bass equilibrium harvest under alternative minimum size and slot limits. Report to Atlantic States Marine Fisheries Commission Striped Bass Technical Committee, 35 p.

DENNEY, N. H., S. JENNINGS, and J. D. REYNOLDS. 2002. Life-history correlates of maximum population 
growth rates in marine fishes. Proc. R. Soc. Lond. B, 269: 2229-2237.

FIELD, J. D. 1997. Atlantic striped bass management: Where did we go right? Fisheries, 22: 6-8.

FRANCIS, R.C. 2003. A web of small tensions. Fisheries, 28: $20-23$.

FRANK, K. T., R. K. MOHN, and J. E. SIMON. MS 1997. Assessment of 4TVW haddock in 1996. Can. Stock Assess. Sec. Res. Doc., No. 107, 90 p.

FRANK, K. T., R. K. MOHN, and J. E. SIMON. MS 2001. Assessment of Div. 4TVW haddock. DFO Can. Sci. Adv. Sec. Res. Doc., 2001/100.

FROMENTIN, J-M., and A. FONTENEAU. 2001. Fishing effects and life history traits: a case study comparing tropical versus temperate tunas. Fish. Res., 53: 133150.

GOODYEAR, C. P. 1985. Relationship between reported commercial landings and abundance of young striped bass in Chesapeake Bay, Maryland. Trans. Am. Fish. Soc., 114: 92-96.

GOODYEAR, C. P., J. E. COHEN, and S. W. CHRISTIANSEN. 1985. Maryland striped bass: recruitment declining below replacement. Trans. Am. Fish. Soc., 114: 146151.

HARDARDÓTTIR, K. MS 2001. Relationship between atresia, fish size and condition in Icelandic cod (Gadus morhua L.). Thesis for Cand. Scien. degree, Department of Fisheries and Marine Biology, University of Bergen, December 2001.

HENDERSON, B. A., T. TRIVEDI, and N. COLLINS. 2000. Annual cycle of energy allocation to growth and reproduction of yellow perch. J. Fish Biol., 57: 122133.

HURLEY, P. C. F., G. A. P. BLACK, P. A. COMEAU, R. K. MOHN, and K. ZWANENBURG. MS 1998. Assessment of 4X haddock in 1997 and the first half of 1998. Can. Stock Assess. Sec. Res. Doc., 98/136, 96 p.

HUTCHINGS, J. A. 1999. Influence of growth and survival costs of reproduction on Atlantic cod, Gadus morhua, population growth rate. Can. J. Fish. Aquat. Sci., 56: 1612-1623.

ICES. MS 1996. Report of the Baltic Fisheries Assessment Working Group. ICES C.M. Doc., No. 1996/Assess:13.

MS 1997. Report of the study group on the precautionary approach to fisheries management. ICES C.M. Doc., No. 1997/Assess:7.

ICES ACFM. MS 1998a. Report of the Study Group on the Precautionary Approach to Fisheries Management. ICES C.M. Doc., No. 1998/ACFM:10, Ref. D.

MS 1998b. Report of the Baltic Fisheries Assessment Working Group. ICES C.M. Doc., No. 1998/ ACFM:16.

MS 1999. Report of the Arctic Fisheries Working Group. ICES C.M. Doc., 1999/ACFM:3.

MS 2001a. Report of the Baltic Fisheries Assessment Working Group. ICES C.M. Doc., No. 2001/ ACFM:18.

MS 2001b. Report of the Arctic Fisheries Working Group. ICES C.M. Doc., No. 2001/ACFM:02.
MS 2001c. Report of the Arctic Fisheries Working Group. ICES C.M. Doc., No. 2001/ACFM:19.

MS 2002a. Report of the Arctic Fisheries Working Group. ICES C.M. Doc., No. 2002/ACFM:18.

ICES ACFM. MS 2002b. Report of the Study Group on the further development of the Precautionary Approach to fisheries management. ICES C.M. Doc., No. 2002/ACFM:10.

MS 2003a. Report of the Study Group on the further development of the Precautionary Approach to fisheries management. ICES C.M. Doc., No. 2003/ ACFM:in press.

MS 2003b. Report of the Study Group on Biological Reference Points for Northeast Arctic cod. ICES C.M. Doc., No. 2003/ACFM: 11.

ICES ACFM. MS 2003c. Report of the Arctic Fisheries Working Group. ICES C.M. Doc., No. 2003/ ACFM:22.

MS 2003d. Report of the Study Group on Growth, Maturity and Condition in Stock Projections. ICES C.M. Doc., No. 2003/D:01.

JAKOBSEN, T., and A. AJIAD. 1999. Management implications of sexual differences in maturation and spawning mortality of Northeast Arctic cod. J. Northw. Atl. Fish. Sci., 25: 125-131.

JAKOBSSON, J., and G. STEFÁNSSON. 1998. Rational harvesting of the cod-capelin-shrimp complex in the Icelandic marine ecosystem. Fish. Res., 37: 7-21.

JOAKIMSSON, G. MS 1969. Fruchtvbarkeitsbestimmungen an Kabeljau, Schellfisch und Hering in islandadischen gewassern. Kieler Meeresforsch., 25: 172180.

KJESBU, O. S., J. KLUNGSYR, H. KRYVI, P. R. WITTHAMES, and M. GREER WALKER. 1991. Fecundity, atresia, and egg size of captive Atlantic cod (Gadus morhua) in relation to proximate body composition. Can. J. Fish. Aquat. Sci., 48: 2333-2343.

KJESBU, O. S., P. R. WITTHAMES, P. SOLEMDAL, and M. GREER WALKER. 1998. Temporal variations in the fecundity of Arcto-Norwegian cod (Gadus morhua) in response to natural changes in food and temperature. J. Sea Res., 40: 303-321.

KÖSTER, F. W., H.-H. HINRICHSEN, M. A. ST. JOHN, D. SCHNACK, B. R. MACKENZIE, J. TOMKIEWICZ, and M. PLIKSHS. 2001a. Developing Baltic cod recruitment models II: Incorporation of environmental variability and species interaction. Can. J. Fish. Aquat. Sci., 58: 1534-1556.

KÖSTER, F. W., C. MÖLLMANN, S. NEUENFELDT, M. PLIKSHS, and R. VOSS. 2001b. Developing Baltic cod recruitment models I: Resolving spatial and temporal dynamics of spawning stock and recruitment for cod, herring and sprat. Can. J. Fish. Aquat. Sci., 58: 15161533.

KÖSTER, F. W., H.-H. HINRICHSEN, D. SCHNACK, M. A. ST. JOHN, B. R. MACKENZIE, J. TOMKIEWICZ, C. MÖllmANN, G. KRAUS, M. PliKShS, A. MAKARCHOUK, and E. ARO. 2003. Recruitment of Baltic cod and sprat stocks: Identification of critical 
life stages and incorporation of environmental variability and spatial heterogeneity into stock-recruitment relationships. Sci. Mar., 67 (Suppl. 1): 129-154.

KRAUS, G., A. MÜLLER, K. TRELLA, and F. W. KÖSTER. 2000. Fecundity of Baltic cod: temporal and spatial variation. J. Fish Biol., 56: 1327-1341.

KRAUS, G., J. TOMKIEWICZ, and F. W. KÖSTER. 2002. Egg production of Baltic cod in relation to variable sex ratio, maturity and fecundity. Can. J. Fish. Aquat. Sci., 59: $1908-1920$.

LAMBERT, T. C. 1990. The effect of population structure on recruitment in herring. J. Cons. int. Explor. Mer, 47: 249-255.

LAMBERT, Y. and J.-D. DUTIL. 1997. Can simple condition indices be used to monitor and quantify seasonal changes in the energy reserves of Atlantic cod (Gadus morhua)? Can. J. Fish. Aquat. Sci., 54(Suppl. 1): 104-112.

LAMBERT Y., N. A. YARAGINA, G. KRAUS, G. MARTEINSDOTTIR, and P. J. WRIGHT. 2003. Using environmental and biological indices as proxies of egg and larval production of marine fish. J. Northw. Atl. Fish. Sci., 33: 115-159 (this volume).

MA, Y., O. S. KJESBU, and T. JØRGENSEN. 1998. Effects of ration on the maturation and fecundity in captive Atlantic herring (Clupea harengus). Can. J. Fish. Aquat. Sci., 55: 900-908.

MARSHALL, C. T., and K. T. FRANK. 1999. The effect of interannual variation in growth and condition on haddock recruitment. Can. J. Fish. Aquat. Sci., 56: 347-355.

MARSHALL, C. T., O. S KJESBU, N. A. YARAGINA, P. SOLEMDAL, and Ø. ULLTANG. 1998. Is spawner biomass a sensitive measure of the reproduction and recruitment potential of Northeast Arctic cod? Can. J. Fish. Aquat. Sci., 55: 1766-1783.

MARSHALL, C. T., N. A. YARAGINA, B. ÅDLANDSVIK, and A. V. DOLGOV. 2000. Reconstructing the stock/ recruit relationship for Northeast Arctic cod using a bioenergetic index of reproductive potential. Can. J. Fish. Aquat. Sci., 57: 2433-2442.

MARTEINSDOTTIR, G., and G. A. BEGG. 2002. Essential relationships incorporating the influence of age, size and condition on variables required for estimation of reproductive potential in Atlantic cod Gadus morhua stocks. Mar. Ecol. Prog. Ser., 235: 235-256.

MARTEINSDOTTIR, G., and H. BJÖRNSSON. MS 1999. Time and duration of spawning of cod in Icelandic waters. ICES C.M. Doc., No. 1999/Y:34: 22 p.

MARTEINSDOTTIR, G., and A. STEINARSSON. 1998. Maternal influence on the size and viability of Iceland cod (Gadus morhua L.) eggs and larvae. J. Fish. Biol., 52: 1241-1258.

MARTEINSDOTTIR, G., and K. THORARINSSON. 1998. Improving the stock-recruitment relationship in Icelandic cod (Gadus morhua L.) by including age diversity of spawners. Can. J. Fish. Aquat. Sci., 55: $1372-1377$.

MARTEINSDOTTIR, G., A. GUDMUNDSDÓTTIR, V. THORSTEINSSON, and G. STEFÁNSSON. 2000a. Spatial variation in abundance, size composition and viable egg production of spawning cod (Gadus morhua L.) in Icelandic waters. ICES J. Mar. Sci., 57: 824-830.

MARTEINSDOTTIR, G., B. GUNNARSSON, and I. M. SUTHERS. 2000b. Spatial variation in hatch date distributions and origin of pelagic juvenile cod in Icelandic waters. ICES J. Mar. Sci., 57: 1184-1197.

MD DNR (Maryland Department of Natural Resources). MS 2001. Investigation of Striped Bass in the Chesapeake Bay. USFWS Federal Aid Project F-42-R-13, 1999-2000. Maryland Fisheries Service, Maryland Department of Natural Resources, Annapolis, Maryland, 213 p.

MORGAN, M. J., W.B. BRODIE, and W. R. BOWERING. MS 1999. An assessment of American plaice in NAFO Divisions 3LNO. NAFO SCR Doc., No. 44, Serial No. N4099, $55 \mathrm{p}$.

MORGAN, M. J., W. B. BRODIE, B. P. HEALEY, D. M. MADDOCK, D. PARSONS, D. STANSBURY, and D. POWER. MS 2001. An assessment of American plaice in NAFO Divisions 3LNO. NAFO SCR Doc. No. 59, Serial No. N4437, 70 p.

MORSE, W. W. MS 1994. Atlantic cod, Gadus morhua, larvae: an analysis of the MARMAP time series, 19771987. NEFSC, Woods Hole Laboratory, Lab. Ref. Doc., No. 94-08.

MUKHINA, N. V. MS 1999. The use of Russian ichthyoplankton survey data in the forecasting of recruitment to Arcto-Norwegian cod stock. ICES C.M. Doc., No. 1999/Y:15, 5 p.

MUKHINA, N. V., C. T. MARSHALL, and N. A. YARAGINA. 2003. Tracking the signal in year-class strength of Northeast Arctic cod through multiple survey estimates of egg, larval and juvenile abundance. J. Sea Res., 50: 57-75.

MURAWSKI, S. A., P. J. RAGO, and E. A TRIPPEL. 2001. Impacts of demographic variation in spawning characteristics on reference points for fishery management. ICES J. Mar. Sci., 58: 1002-1014.

MURUA, H., G. KRAUS, F. SABORIDO-REY, P. R. WITTHAMES, A. THORSEN, and S. JUNQUERA. 2003. Procedures to estimate fecundity of wild collected marine fish in relation to fish reproductive strategy. J. Northw. Atl. Fish. Sci., 33: 33-54 (this volume).

MYERS, R. A., and N. J. BARROWMAN. 1996. Is fish recruitment related to spawner abundance? Fish. Bull. U.S., 94: 707-724.

NAFO. MS 1997. Report of the Ad hoc Working Group of the NAFO Scientific Council on the Precautionary Approach. NAFO SCS Doc., No. 12, Serial No. N2911, $61 \mathrm{p}$.

MS 1998. Report of the Scientific Council workshop on the precautionary approach to fisheries management. NAFO SCR Doc. No. 76, Serial No. N3069, $62 \mathrm{p}$.

MS 2000. Scientific Council Reports 2000. Dartmouth, Canada. 2000, 303 p.

NAFO. MS 2001. Scientific Council Reports 2001. Dartmouth, Canada. 2001, 339 p.

NASH, R.D.M. 1998. Exploring the population dynamics 
of Irish Sea plaice, Pleuronectes platessa L., through the use of Paulik diagrams. J. Sea Res. 40: 1-18.

NEFSC (Northeast Fisheries Science Center). MS 2002. Final report of the working group on re-evaluation of biological reference points for New England Groundfish. NEFSC, Woods Hole Laboratory, Lab. Ref. Doc., No. 02-04.

O'BRIEN, L., P. RAGO, P. BERRIEN, and R. G. LOUGH. 2003. Incorporating early-life history parameters in the estimation of the stock-recruit relationship of Georges Bank Atlantic cod (Gadus morhua). J. Northw. Atl. Fish. Sci., 33: 191-205 (this volume).

OLSEN, E. J., and R. A. RULIFSON. 1992. Maturation and fecundity of Roanoke River-Albemarle Sound striped bass. Trans. Am. Fish. Soc., 121: 524-537.

OOSTHUIZEN, E., and N. DAAN. 1974. Egg fecundity and maturity of North Sea cod, Gadus morhua. Neth. J. Sea Res., 8: 378-397.

PAINTING, S. J., L. HUTCHINGS, J. A. HUGGETT, J. L. KORRÛBEL, A. J. RICHARDSON, and H. M. VERHEYE. 1998. Environmental and biological monitoring for forecasting anchovy recruitment in the southern Benguela upwelling region. Fish. Oceanogr., 7: 364-374.

RICHARDS, R. A, and P. J. RAGO. 1999. A case history of effective fishery management: Chesapeake Bay striped bass. North Am. J. Fish. Manage., 19: 356-375.

RIDEOUT, R. M., M. P. M. BURTON, and G. A. ROSE. 2000. Observations on mass atresia and skipped spawning in northern Atlantic cod, from Smith Sound, Newfoundland. J. Fish Biol., 57: 1429-1440.

ROSE, G. A., and R. L. O'DRISCOLL. 2002. Capelin are good for cod: can the northern stock rebuild without them? ICES J. Mar. Sci., 59: 1018-1026.

ROTHSCHILD, B. J., and M. J. FOGARTY. 1989. Spawning-stock biomass: a source of error in recruitment/stock relationships and management advice. ICES J. Cons., 45: 31-135.

SABORIDO-REY, F., and S. JUNQUERA. 1998. Histological assessment of the variations in sexual maturity of cod (Gadus morhua) in Flemish Cap (Northwest Atlantic). ICES J. Mar. Sci., 55: 515-521.

SCHOPKA, S. A. 1971. Vergleichende Untersuchungen zur Fortpflanzungsrate bei Herings-und Kabeljaupopulationen (Clupea harengus L. und Gadus morhua L.) Bericht. Deut. Wissenschaft. Komm. Meeresfor., 22: 31-79.

SCHÜLEIN, F. H., A. J. BOYD, and L. G. UNDERHILL. 1995. Oil-to-meal ratios of pelagic fish taken from the northern and the southern benguela systems: seasonal patterns and temporal trends, 1951-1993. S. Afr. J. Mar. Sci., 15: 61-82.

SCOTT, B., G. MARTEINSDOTTIR, and P. WRIGHT. 1999. Potential effects of maternal factors on spawning stock - recruitment relationships under varying fishing pressure. Can. J. Fish. Aquat. Sci., 56: 1882-1890.

SECOR, D. H. 2000a. Spawning in the nick of time? Effect of adult demographics on spawning behavior and recruitment of Chesapeake Bay striped bass. ICES J.
Mar. Sci., 57: 403-411.

SECOR, D. H. 2000b. Longevity and resilience of Chesapeake Bay striped bass. ICES J. Mar. Sci., 57: 808-815.

SECOR, D. H., T. M. TRICE, and H. T. HORNICK. 1995. Validation of otolith-based ageing and a comparison of otolith- and scale-based ageing in mark-recaptured Chesapeake Bay striped bass, Morone saxatilis. Fish. Bull. U.S., 93: 186-190.

SHAPIRO, L. A. 1988. Correlation between the quantity and quality of the gonads in the Baltic cod. FischereiForschung, 26: 66-69.

SOLEMDAL, P. 1997. Maternal effects - a link between the past and the future. J. Sea Res., 37: 213-227.

SPARHOLT, H., and J. TOMKIEWICZ. 2000. A robust method to compile trawl survey data applied in assessment of Central Baltic cod. Arch. Fish. Mar. Res., 48: $125-151$.

STENSETH, N. C., A. MYsterud, G. OTTERSEN, J. W. HURRELL, K.-S. CHAN, and M. LIMA. 2002. Ecological effects of climate fluctuations. Science, 297: 1292-1296.

THORSEN, A. and O. S. KJESBU. 2001. A rapid method for estimation of oocyte size and potential fecundity in Atlantic cod using a computer-aided particle analysis system. J. Sea Res., 46: 295-308.

TOMKIEWICZ, J., M. ERIKSSON, T. BARANOVA, V. FELDMAN, and H. MÜLLER. MS 1997. Maturity ogives and sex ratios for Baltic cod: establishment of a database and time series. ICES C.M. Doc., No. 1997/ CC:20, 22 p.

TOMKIEWICZ, J., M. J. MORGAN, J. BURNETT, and F. SABORIDO-REY. 2003. Available information for estimating reproductive potential of Northwest Atlantic groundfish stocks. J. Northw. Atl. Fish. Sci., 33: 1-21 (this volume).

TRIPPEL, E.A. 1999. Estimation of stock reproductive potential: history and challenges for Canadian Atlantic gadoid stock assessments. J. Northw. Atl. Fish. Sci., 25: $61-81$.

UPHOFF, J. 1993. Determining striped bass spawning stock status from the presence or absence of eggs in ichthyoplankton survey data. N. Am. J. Fish. Manage., 13: $645-656$.

UPHOFF, J. 1997. Use of egg presence-absence to derive probability-based management criteria for upper Chesapeake Bay striped bass. N. Am. J. Fish. Manage., 17: 645-656.

U.S. DEPARTMENT OF COMMERCE. MS 1998. Magnuson-Stevens Act provisions; National standard guidelines, Final rule. Federal Register, May 1, 1998: 24211-24237.

VALLIN, L., and A. NISSLING. 2000. Maternal effects on egg size and egg buoyancy of Baltic cod, Gadus morhua Implications for stock structure effects on recruitment. Fish. Res., 49: 21-37.

VETTER, E. F. 1988. Estimation of natural mortality in fish stocks: a review. Fish. Bull. U.S., 86: 25-43.

VÁZQUEZ, A., and S. CERVIÑO. MS 2001. A review of the status of the cod stock in NAFO Division $3 \mathrm{M}$. 
NAFO SCR Doc., No. 60, Serial No. N4438, 13 p. VÁZQUEZ, A., L. MOTOS, and J.-C MAHÉ. MS 1999. An assessment of the cod stock in NAFO Division 3M. NAFO SCR Doc., No. 56, Serial No. N4115, $25 \mathrm{p}$.

WARE, D. M. 1980. Bioenergetics of stock and recruitment. Can. J. Fish. Aquat. Sci., 37: 1012-1024.

WIELAND, K. 1995. Einfluß der Hydrographie auf die Verikalverteilung und Sterblichkeit der Eier des Ostseedorsches (Gadus morhua callarias) im Bornholm Becken, südliche zentrale Ostsee. Ber. Inst. Meereskunde, Kiel, 266: 114 p.

WIELAND, K., A. JARRE-TEICHMANN, and K. HORBOWA. 2000. Changes in the timing of spawning of
Baltic cod: possible causes and implications for recruitment. ICES J. Mar. Sci., 57: 452-464.

WITTHAMES, P. R., and M. GREER WALKER. 1995.

Determinacy of fecundity and oocyte atresia in sole (Solea solea) from the Channel, North Sea and the Irish Sea. Aquat. Living Res., 8: 91-109.

YARAGINA, N. A., and C. T. MARSHALL. 2000. Trophic influences on interannual and seasonal variation in the liver condition index of Northeast Arctic cod (Gadus morhua). ICES J. Mar. Sci., 57: 42-55.

ZASTROW, C. E., E. D. HOUDE, and E. H. SAUNDERS. 1989. Quality of striped bass (Morone saxitalis) eggs in relation to river source and female weight. ICES Proc.Verb., 191: 24-42. 